\title{
Job Polarization and the Flattening of the Price Phillips Curve
}

\section{Daniele Siena ${ }^{1}$ and Riccardo Zago ${ }^{2}$}

June 2021, WP 819

\begin{abstract}
This paper shows that the change in the occupational composition of the labor market in favour of non-routine jobs -i.e. job polarization- flattens the price Phillips Curve (PC). Using data from the European Monetary Union and exploiting the fact that job polarization accelerates during recessions, we obtain two results. First, countries experiencing a bigger shift in the occupational structure during a downturn exhibit a flatter PC afterward. Second, the occupational shifts experienced during the Great Recession and the Sovereign Debt Crisis explain up to a forth of the flattening of the curve in the 2002-2018 period. We reconcile this evidence through a New Keynesian model with unemployment and search and matching frictions. Heterogeneity in the fluidity across segments of the labor market -i.e. differences in the separation and hiring rate across jobs- is the source of PC flattening.
\end{abstract}

Keywords: Phillips Curve, Job Polarization, Occupational Composition, Monetary Policy, Labor Market Fluidity.

JEL classification: E31, E32, J21.

\footnotetext{
${ }^{1}$ Banque de France. daniele.siena@banque-france.fr.

${ }^{2}$ Banque de France. riccardo.zago@banque-france.fr.

We thank Cristiano Cantore, Jordi Gali, Basile Grassi, Nicolas Petrosky-Nadeau, Tommaso Monacelli, Gianluca Violante and PSE-BDF workshop, AMSE-BDF workshop, Canadian Economic Association Annual Meeting 2021, European Economic Association Annual Meeting 2021, CEF 2021, International Conference on European Studies 2021, IAAE 2021, Bocconi brown bag seminar participants for their helpful comments and suggestions. The views expressed in this paper are those of the authors and do not necessarily reflect those of the Banque de France. All the remaining errors are ours.
}

Working Papers reflect the opinions of the authors and do not necessarily express the views of the Banque de France. This document is available on publications.banque-france.fr/en 


\section{NON-TECHNICAL SUMMARY}

In the European Monetary Union (EMU), the negative relationship between price inflation and unemployment -the price Phillips Curve (PC)- has recently weakened. At the same time, the share of routine employment has declined, giving rise to a phenomenon called job polarization. This paper combines these two apparently unrelated facts and shows that the change in the occupational composition of the labor market is an important driver of the flattening of the PC. In other words, the paper highlights the importance of labor market characteristics, and in particular the heterogeneity across occupations, for the structural relationship between prices and unemployment.

The contribution of the paper is both empirical and theoretical. In the empirical part, first it shows that countries abundant of routine jobs exhibit a steeper PC. Conversely, countries abundant of non-routine jobs exhibit a flatter PC. Then, it exploits the fact that recessions temporarily accelerate the long-run trend of polarization. By using the cross-country cyclical heterogeneity in routine job destruction, we prove that each time the employment composition of the labor market changes in favor of non-routine jobs, the slope of the PC flattens afterward. Hence, we are able to assess that the shift in the employment composition matured during the Great Recession and Sovereign Debt Crisis can explain 25\% of the flattening of the PC in the EMU.

In the theoretical part of the paper, we investigate why employment relocation from routine to non-routine jobs has implication for the price PC. The answer lies in differences across occupations. On the one hand, the market of non-routine jobs is more fluid, i.e. it exhibits higher separation and hiring rates. Conversely, the market of routine job is less fluid, i.e. it exhibits lower separation and hiring rates. We use a standard New Keynesian model with search and matching frictions to analyse how this occupational heterogeneity is important for the slope of the New Keynesian Phillips Curve. In particular, we show that an overall higher labor market fluidity implies a flatter price PC. Therefore, employment relocation from less to more fluid jobs - from routine to non-routine occupations - weakens the relation between inflation and unemployment.

The empirical and theoretical analysis allows to conclude that the occupational composition of the labor market -and in particular the heterogeneity across jobs- matters for the slope of PC. Any change in the composition has direct implications for the relation between prices and unemployment. This is an important fact for for monetary policy, especially in light of recent macro-trends affecting the labor market such as job polarization. 
Figure 1 : The Slope of the Phillips Curve and Job Polarization

(a)

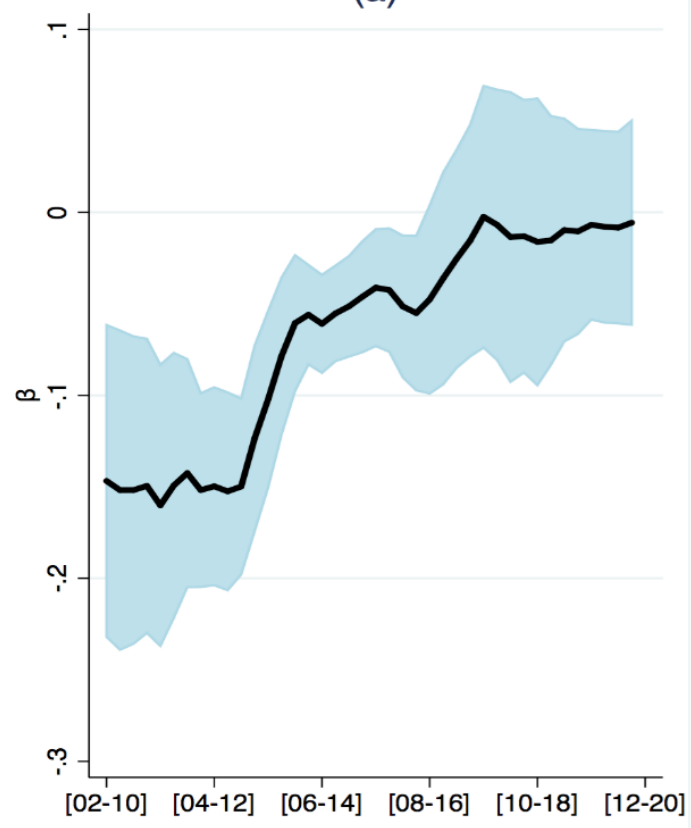

(b)

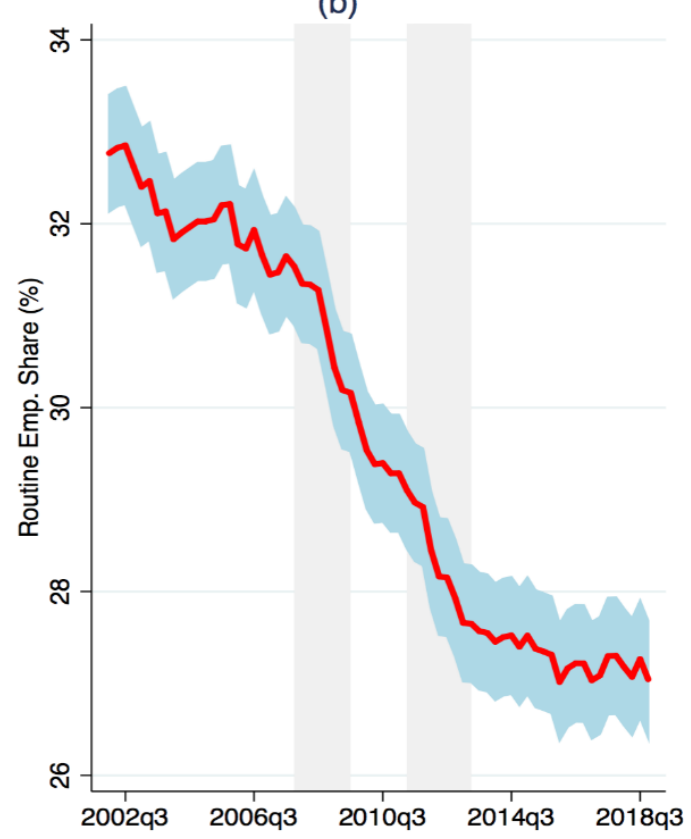

Note : Figure 1.a and 1.b plots respectively the slope of the Phillips Curve and the routine employment share across the EMU. Grey areas represent the Great Recession and the Sovereign Debt Crisis. Light-blue shaded areas represent $95 \%$ confidence intervals.

\section{Polarisation des emplois et aplatissement de la courbe de Phillips}

\section{RÉSUMÉ}

Cet article montre que l'augmentation de la part des emplois non routiniers - c'est-à-dire la polarisation de l'emploi - aplatit la courbe de Phillips. En utilisant les données de l'Union Monétaire Européenne et en exploitant le fait que la polarisation s'accélère pendant les récessions, nous obtenons deux résultats. Premièrement, les pays qui ont vécu un changement plus important dans la structure professionnelle pendant une récession ont une courbe de Phillips plus plate par la suite. Deuxièmement, les changement du marché du travail vécus lors de la Grande Récession et de la Crise de la Dette Souveraine expliquent jusqu'à un quart de l'atténuation de la courbe sur la période 2002-2018. Nous réconcilions ces faits stylisés à l'aide d'un modèle néo-keynésien avec chômage et frictions sur la marché du travail . L'hétérogénéité de la fluidité entre les segments du marché du travail - c'est-à-dire les différences des taux de séparation et d'embauche - est la source de l'atténuation de la courbe de Phillips.

Mots-clés : courbe de Phillips, polarisation des emplois, composition professionnelle, politique monétaire, fluidité du marché du travail.

Les Documents de travail reflètent les idées personnelles de leurs auteurs et n'expriment pas nécessairement la position de la Banque de France. Ils sont disponibles sur publications.banque-france.fr 


\section{Introduction}

In the European Monetary Union (EMU), the negative relationship between price inflation and unemployment -the price Phillips Curve (PC)- has recently weakened (see Figure $1(\mathrm{a})$ ). Contemporaneously, the share of routine employment has declined, giving rise to a phenomenon called job polarization (see Figure 1(b)). ${ }^{1}$ The contribution of this paper is to combine these two apparently unrelated events to show how job polarization has been a crucial driver of the flattening of the PC in the EMU. In other words, this paper demonstrates that the occupational composition of the labor market and -therefore- heterogeneity across jobs matter for the structural relationship between prices and unemployment.

Fig. 1. The Phillips Curve and the Routine Employment Share in the EMU

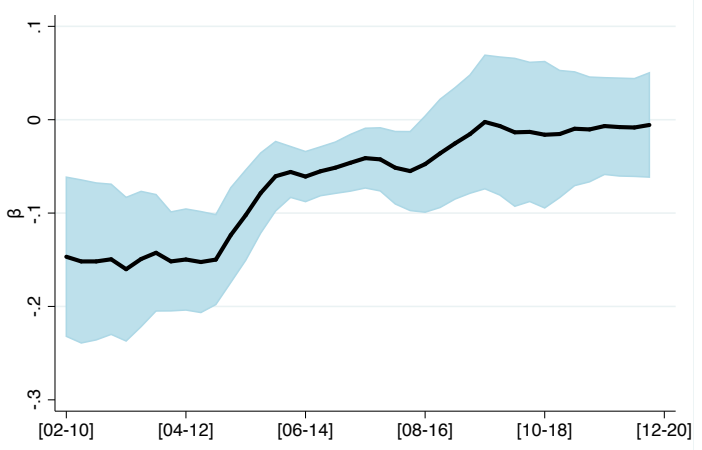

(a) The Phillips Curve

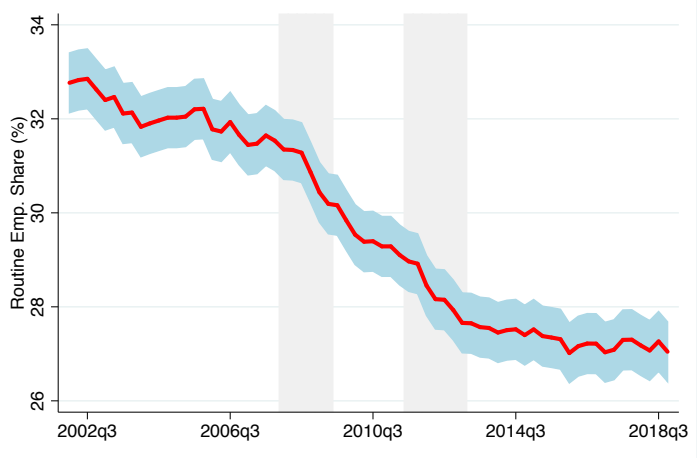

(b) The Routine Share

Note: Figure 1(a) plots the coefficient of the Phillips Curve estimated over 8-year rolling windows for those countries that joined the EMU before 2002 (Luxembourg excluded). The estimating equation for each window is $\Delta \log (p)_{i, t}=\alpha_{i}+\beta u_{i, t-1}+X_{i, t-1}^{\prime} \gamma+$ $\epsilon_{i, t}$, where $\Delta \log (p)_{i, t}$ is the year-on-year log-change of the harmonized consumer price index (energy and food excluded) in country $i ; \alpha_{i}$ is the country fixed-effect; $u_{i, t-1}$ is the unemployment gap measured as deviation of the unemployment series from a linear trend; $X_{i, t-1}^{\prime}$ is a vector of controls including lagged inflation, past expectations on current inflation, the change in the import price index, and a dummy for each country-specific business cycle phase; $\epsilon_{i, t}$ is the error term. The light-blue-shaded area represents the $95 \%$ confidence interval. Data is at quarterly frequency. Figure 12(b) plots the evolution of the average abstract employment share from 2002q1 to 2018q4 across the 11 EMU countries. The routine employment share is defined as the sum of employment in clerical, craft and plant occupations over total employment. The light-blue-shaded area represents the $95 \%$ confidence interval. The two grey-shaded areas indicate respectively the periods of the Great Recession and of the Sovereign Debt Crisis as defined by the CEPR Business Cycle Committee. Data is at quarterly frequency.

Both in Europe and in the U.S., economists broadly agree that the price PC has weakened and it has almost flattened in the aftermath of the Great Recession of 2008. This fact has become of great concern among central bankers since a flatter Phillips Curve prevents monetary policy to be effective when trying to stabilize prices (as in the EMU), unemployment or both (as in the US). For this reason, a good deal of research was conducted to properly assess to

\footnotetext{
${ }^{1}$ The same two facts are observed in the US. See Del Negro, Lenza, Primiceri and Tambalotti (2020) for the evolution of the price Phillips Curve and Jaimovich and Siu (2020) for the dynamics of routine shares.
} 
which extent the PC has died, and why this has happened. The literature has so far proposed explanations that can be grouped in two not mutually exclusive categories. The first focusing on inflation expectations and the stronger ability/commitment of central banks to keep inflation low (e.g. Blanchard (2016)). The second studying the impact of structural changes in the economy, like demographic transition, technological progress, globalization and labor market transformations (see, among others Guerrieri, Gust and López-Salido (2010) and Faccini and Melosi (2020)). We contribute to the latter group by providing (theory-backed) empirical evidence that changes in the occupational structure of the labor market has critical relevance for the slope of the PC.

To do this, we leverage on recent developments in the job-polarization literature, which documents that the disappearance of routine jobs (clerical and production occupations) is not only a long-run phenomenon, but it has also cyclical features. In fact, as demonstrated in Jaimovich and Siu (2020) for the U.S., job polarization accelerates during downturns. In other words, the cycle leads to (out of trend) shifts in the occupational composition of the labor market in favour of non-routine jobs (professional, managerial, services and sales occupations). Given this, we first provide evidence that the long-run and cyclical properties of job polarization hold also in the EMU. In particular, we show that the decline of the routine employment share is very homogeneous across EMU members in normal times. Conversely, the Great Recession (GR) and the following Sovereign Debt Crisis (SDC) operate on the common long-run trend of job polarization through occupational shifts, which are very heterogeneous across countries and recessions. More importantly for identification purposes, these occupational shifts depend on the depth and length of the downturn rather than on pre-recession (i.e. labor or product market) country characteristics. Hence, we exploit these exogenous and heterogeneous compositional changes to assess if and by how much the disappearance of routine jobs affected the relationship between prices and the real economy.

Our main finding is that countries experiencing a bigger change in the composition of the job ladder during a recession exhibit a flatter PC afterwards. In particular, the occupational shifts witnessed during the last two recessions in the EMU explain up to a forth of the flattening of the price PC observed in the last ten years. These results are robust to (i) controlling for other structural breaks, (ii) controlling for changes in the sectorial composition of the economy (i.e. for the transition towards a service economy), (iii) several definitions of price inflation and unemployment gap, and (iv) different country/data sample selection. Therefore, we conclude that the composition of the labor market matters for the slope of the price PC. ${ }^{2}$

\footnotetext{
${ }^{2}$ Although this paper focuses on the price PC, it is not silent on the wage PC. Under the same identification strategy, we do not find any evidence that employment composition matters for the recent evolution of the
} 
But, why is this the case? The answer is in the differences between the surviving and disappearing jobs, i.e. between non-routine and routine occupations. As suggested by the polarization literature, these jobs are very different in several dimensions. For example, routine tasks can be easily automated whereas non-routine tasks cannot; ICT investments increase labor productivity of non-routine workers while they trigger displacement of routine workers; routine jobs are very sensitive to trade shocks whereas abstract jobs are not. Here we highlight another important difference between the two types of occupations: the market of non-routine jobs is characterized by a higher separation and hiring rate with respect to the market of routine jobs.

Hence, we take the standard New Keynesian model with unemployment and search-andmatching friction of Blanchard and Galí (2010) and we derive the analytical relationship between the slope of the PC and labor market characteristics. Under this framework, we prove that increasing the fluidity of the labor market (higher job separation and hiring rate) indeed flattens the price Phillips Curve. This analysis clarifies the channel through which the relocation of employment from routine to non-routine occupations -i.e. job polarizationis important for the price Phillips Curve since it leads to an overall increase of fluidity of the labor market.

Literature review - This paper relates to two strands of the literature. The first one is on job polarization, which documents the long-run falling of employment in jobs with high content of routine tasks (among the many, see Acemoglu (2002), Autor, Katz and Kearney (2006), Acemoglu and Autor (2011)). In this literature, this phenomenon is typically explained by technological change: throughout time, new and cheaper technologies allow the substitution of man-work with machines in performing routine tasks, whereas it complements workers in performing non-routine tasks (see for example Autor (2007) and Acemoglu and Restrepo (2017)). The second source of polarization usually cited in the literature is international trade and globalization. In fact, trade and offshoring allow respectively to substitute home routine productions with imports and to move routine activities in countries with lower labor costs (see Autor, Dorn and Hanson (2013) and Autor, Dorn and Hanson (2015)) so to trigger the decline of home routine employment.

Yet, this long-run phenomenon has also cyclical properties. As explained in Jaimovich and Siu (2020) and Gaggl and Kaufmann (2019) for the U.S., the long-run trend of job polarization accelerates during downturns, with routine jobs being permanently destroyed. As mentioned above, we show that this property holds also for EMU countries and we leverage

wage PC. As discussed in Section 3.4 and in Appendix D.2, we find that only sectorial dynamics (rather than occupational dynamics) affect the slope of the wage PC. 
on it to study its implications for the PC. Moreover, since we show that the fluidity of the job market is important for the $\mathrm{PC}$, our paper relates to that niche in the literature showing how technical change and polarization can also explain the de-unionization of the workforce (see for example Foster, Grim and Haltiwanger (2016), Açıkgöz and Kaymak (2008), Dinlersoz and Greenwood (2016) and Acemoglu, Aghion and Violante (2001)).

The second strand of the literature is on the flattening of the Phillips Curve, and it is both empirical and theoretical. On the empirical side, the work is abundant on both shores of the Atlantic. For the U.S., Blanchard (2016), Murphy (2018) and Powell (2018) state that the PC is still alive, but its slope became flatter already from the 80's on, while inflation expectations have become more anchored. In the same direction go Hooper, Mishkin and Sufi (2020), Fitzgerald, Nicolini et al. (2014), Mavroeidis, Plagborg-Møller and Stock (2014). McLeay and Tenreyro (2020) show that this evolution over time of the PC is true also at state and city level, although the correlation between unemployment and inflation is stronger than in the aggregate time series. Hazell, Herreo, Nakamura and Steinsson (2020), using a multi-region model, show that the slope of the Phillips curve is small and was small even during the early 1980s. On the other hand, Del Negro et al. (2020) offer evidence that the flattening has started in the 90's along with a progressive flattening of the aggregate supply curve. All these papers point out that the flattening is therefore less recent than we thought, and not entirely explained by the Great Recession.

For the EMU, Ball and Mazumder (2019), Moretti, Onorante and Zakipour-Saber (2019), Deroose, Stevens et al. (2017) and Berson, de Charsonville, Diev, Faubert et al. (2018) show that the price PC has flattened from the financial crisis of 2008, but the structural relation between price dynamics and unemployment and other variables of economic slack still exists. In disagreement with this view is Giannone, Lenza, Momferatou and Onorante (2014), which show that the PC actually was steeper during the GR, whereas Ciccarelli and Osbat (2017) show that the disconnection between prices and unemployment started after 2012 due to both structural and cyclical factors that have affected aggregate demand.

In both continent, one of main explanations for the flattening of the PC is that inflation expectations have become more important than past (lagged) inflation to explain current price dynamics. Moreover, it has become way more firmly anchored than in the past as the Fed and the ECB have more clearly committed to their inflation objectives. This view has been analyzed and expressed in a wide range of research, Fed and ECB communications, including among others, Roberts (2004), Bernanke (2007), Mishkin (2011), Kiley et al. (2015), Yellen et al. (2015), Pfajfar and Roberts (2018), Ng, Wessel and Sheiner (2018) for the US, and Draghi (2015), Natoli and Sigalotti (2017), Speck (2016), Dovern and Kenny (2017), Ciccarelli, Garcia and Montes-Galdón (2017) and Bobeica and Jarocinski (2017) for Europe. 
Other explanations of the flattening have focused more on structural changes in economic fundamentals, for example due to demographic dynamics or technological changes. Daly, Hobijn and Pyle (2016) show that the shifting composition of the labor force - due to the retirement of baby-boomers- has imparted a downward bias to aggregate wage inflation thus affecting the PC. The importance of demographic dynamics for inflation and inflation expectations is documented also in Yoon, Kim and Lee (2018), Pfajfar and Santoro (2008), Bruine de Bruin, Vanderklaauw, Downs, Fischhoff et al. (2010) which show -in summarythat aging population is deflationary. On the role of technology, Mincer and Danninger (2000), Ciccarelli and Osbat (2017), Jorgenson (2001), Akerlof, Dickens, Perry, Gordon et al. (1996) and many others show that the technological innovation, digitalization, automation and ICT contributes to the long-run downward trend of inflation and its recent dynamics.

Additionally, our paper is related to a growing literature emphasizing the role of labor market dynamics and characteristics. Ravenna and Walsh (2008) estimate a New Keynesian $\mathrm{PC}$ with a frictional labor market and show that search-and-matching frictions are important for a better fit of the price PC with the data. Moscarini and Postel-Vinay (2017) introduce on-the-job search in a New Keynesian model and show that cyclical labor misallocation leads to deflation. Through a similar theoretical set-up, Faccini and Melosi (2020) stress the importance of mobility of workers on the job ladder to rationalize the missing inflation and a flatter PC in the post-GR era. Finally, Cantore, Ferroni and Len-Ledesma (2020) highlight how it is important to look at labor market dynamics, as the labor market share, to correctly model the relationship between the real economy and prices. We contribute to this literature by showing that labor market fluidity is another important channel to explain the recent evolution of the price PC. Parallel to the literature on the price PC, there is another strand focusing on the wage PC. For example, Leduc, Wilson et al. (2017) show that, in the U.S., also the relationship between wages and unemployment flattened since the Great Recession. As explained in Daly and Hobijn (2014), Benigno and Ricci (2011), Schmitt-Grohé and Uribe (2013), downward wage rigidities are important to rationalize this fact. Conversely, Petrosky-Nadeau, Wasmer and Weil (2021) show that efficient rent-sharing between consumers and producers in the goods market drives down wage bargaining and cause the flattening of the wage PC. While these papers provide evidence for a flattening of the wage PC in the U.S., evidence for the Euro Area point toward a steepening. In line with our result of section 3.4, Bulligan and Viviano (2017) find that the wage PC has been steepening in the Euro Area.

Our paper is organized as follows. Section 2 presents the data and facts on job polarization in the EMU. Section 3 estimates an augmented price Phillips Curve for the EMU which takes into account changes in the occupational structure of the labor market. Section 4 
uses a theoretical model to highlight the channels through which job polarization can affect the slope of the price PC and gives micro-evidence that heterogeneity among surviving and non-surviving jobs is key for our result. Section 5 concludes.

\section{Data and Labor Market Dynamics in the EMU}

\subsection{Data, Definitions and Sample Selection}

Our focus is on the European Monetary Union. In particular on the countries that joined the EMU from the beginning: Austria, Belgium, Finland, France, Germany, Greece, Ireland, Italy, Luxembourg, Netherlands, Portugal and Spain. We do it for two reasons. First, countries that joined the EMU more recently have very peculiar convergence trajectories in terms of inflation and employment. Additionally, their entrance in the EMU in some cases coincides with the beginning of a downturn (e.g. see Estonia). Therefore, it would be inappropriate to use our identification strategy for these set of countries. ${ }^{3}$ Second, late entrants have very unreliable employment and unemployment series. Unfortunately, Luxembourg suffers the same problem with employment data. We therefore decide to exclude it from the analysis. As a result, we end-up with 11 countries (EMU11) and consider data from 2002q1 until $2018 \mathrm{q} 4$.

Data comes from three main sources: the Eurostat, the ECB Data Warehouse and the ECB Surveys of Professional Forecasters. Eurostat gives information on employment by occupation, according to the International 2008 Standard Classification of Occupations (ISCO08). We consider employment series for workers in the 15-74 age bracket. Once these series are corrected from statistical breaks and changes in occupation classification, ${ }^{4}$ we follow Jaimovich and Siu (2020) and group these jobs in three major categories based on their task-content: (i) managers, professionals, technical and associate professionals, armed force employees as abstract workers; (ii) clerical, craft and plant employees as routine workers; (iii) elementary, skilled agricultural, forestry and fishery employees, sales and service workers as manual workers. Finally, under this grouping, we build employment shares series for each category. Eurostat is also used to build the quarterly series of the unemployment rate for population in the 15-74 age bracket and the year-on-year change in the import price index.

The ECB Data Warehouse and the ECB Survey of Professional Forecasters (SPF) provide information on prices and expected inflation by country. In particular, we use the Harmonized Consumer Price Index (excluded energy and food) to build year-on-year infla-

\footnotetext{
${ }^{3}$ For details on the identification strategy, refer to Section 3.1 .

${ }^{4}$ See Appendix A.1 for details.
} 
tion rate at quarterly frequency, and the SPF for forecast for expected inflation at quarterly frequency. ${ }^{5}$ We use also the ECB Data Warehouse to extrapolate country-specific business cycle dates from the time series of real GDP: for each country, we define as a recession a period in which GDP falls for at least two consecutive quarters. The peak of the recession is identified as the last quarter before which real GDP starts falling and the trough of the recession as the last quarter after which real GDP starts increasing again for at least two consecutive quarters. ${ }^{6}$ This allows us to punctually identify in which phase of the business cycle every country is in every quarter.

\subsection{Job Polarization in the EMU11}

Fig. 2. Abstract and Manual Share across the EMU11

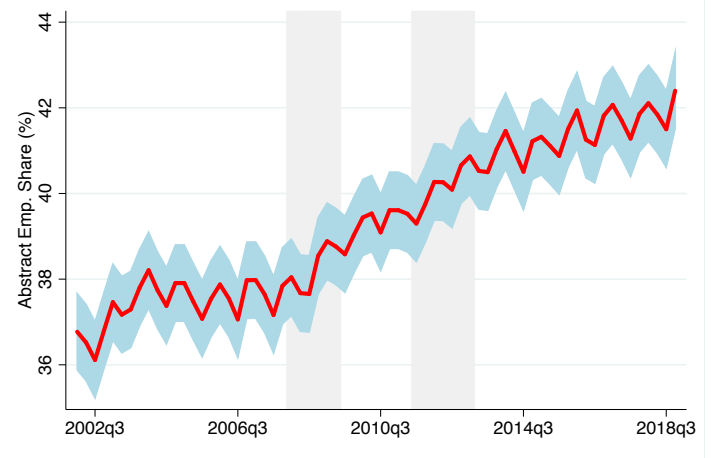

(a) Abstract Share

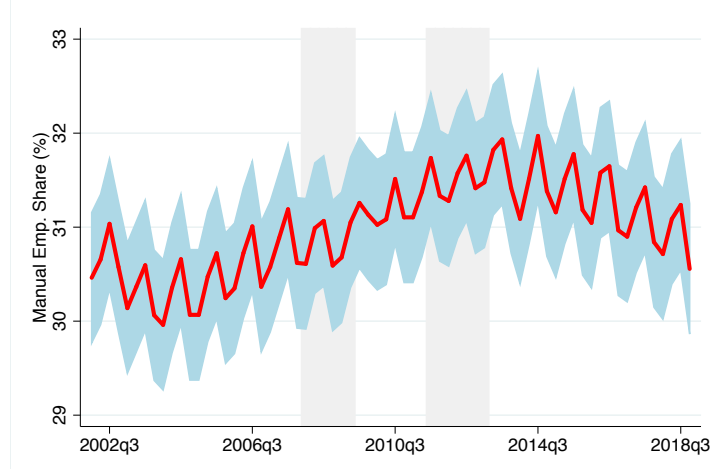

(b) Manual Share

Note: Figure 2(a) plots the evolution of the mean abstract employment share from 2002q1 to 2018q4 for those countries that joined the EMU before 2002 (Luxembourg excluded). The abstract employment share is defined as the sum of employment in managerial, professional, technical and associate professional, and armed force occupations over total employment. Figure 2(b) plots the evolution of the mean manual employment share from 2002q1 to 2018q4 for the same 11 EMU countries. The manual employment share is defined as the sum of employment in elementary, skilled agricultural, forestry and fishery, sales and services occupations over total employment. The light-blue-shaded area represents the $95 \%$ confidence interval. The two grey-shaded areas indicate respectively the periods of the Great Recession and of the Sovereign Debt Crisis as defined by the CEPR Business Cycle Committee. Data is at quarterly frequency and not-seasonally adjusted.

The large literature on job polarization documents the long-run falling of employment in jobs with a high content of routine tasks (among the many see Acemoglu (2002), Autor et al. (2006), Goos and Manning (2007) and Acemoglu and Autor (2011)). Yet, this long-run trend has a short-run counterpart. As shown in Jaimovich and Siu (2020) for the U.S., job polarization accelerates during recessions with job-losses concentrated the most in routine occupations. We leverage on these results for the U.S. and show that both the long and

\footnotetext{
${ }^{5}$ See Appendix A.4 for details.

${ }^{6}$ See Appendix A.3 for full list of country-specific business cycle dates along with plots of real GDP series and recession brackets in accordance with our business-cycle dates definition.
} 
short-run properties of job polarization hold for countries in the EMU11 as well. As Figure 1(b) displays, the share of routine employment across EMU11 countries have been following a downward trend. From the beginning of the Great Recession (GR) until the end of the Sovereign Debt Crisis (SDC), the process of polarization accelerated and the downward trend became steeper. Afterward, the routine share have returned to the pre-GR trend. However, this first-sight analysis is confounding since it looks that the trend accelerated without interruption until the end of the SDC, and without any effect of the economic expansion between the two crisis. But, if "job polarization follows the cycle" -as explained in Jaimovich and Siu (2020) - we should observe a change in the trend in every single phase of the business cycle, i.e. in every single contractionary and expansionary phase. In order to check this point, we estimate the following expression:

$$
\text { Share }_{i, t}^{R}=\alpha_{i}+\beta_{1} \text { time }+\beta_{2} \text { phase }_{i, t}+\beta_{3} \text { phase }_{i, t} \times \text { time }+\epsilon_{i, t}
$$

where $S h a r e_{i, t}^{R}$ is the routine employment share at time $t$ in country $i, \alpha_{i}$ is the country fixed effect, time is the number of quarters, phase $_{i}=$ [Before GR, GR, Between GR and SDC, $\mathrm{SDC}$, After SDC] is a vector of mutually exclusive dummies taking value one if, at time $t$, country $i$ is currently in that cyclical phase. The phase $e_{i}$ time-dummy is country specific, i.e. we use country specific business cycle dates to define the beginning and the end of each recession, as explained in Section 2.1. $\epsilon_{i, t}$ is the error term.

Table 1 shows results from this panel regression. From column (1), we see that -between 2002q1 and 2018q4- the routine employment share follows a downward trend across countries, with an average decline of $0.10 \mathrm{pp}$ every quarter. In column (2), we investigate how much of this decline is imputable to each different phase of the business cycle. Before the GR, the routine share is decreasing by $0.06 \mathrm{pp}$ every quarter. When entering the GR, the trend accelerates by five times across all countries. Between the two recessions, the slope of the trend is not significantly different from the slope estimated in pre-GR periods. When EMU11 economies enter the SDC, the trend of job-polarization returns to accelerate at a pace two times bigger than before the GR. Once EMU11 countries are out of the SDC, again there is no statistical difference between pre-GR and post-SDC trends. This empirical evidence generalizes the results of Jaimovich and Siu (2020) and proves that, also in the EMU, job polarization has not only a long-run driver but also a cyclical component: there is a negative trend in routine employment, which temporarily accelerates every time the economy enters a recession.

What about the dynamics of other jobs? Figure 2(a) and 2(b) show respectively the evolution of the employment share of abstract and manual jobs. While both present strong 
Table 1: Trend Decomposition of Occupational Shares across the EMU11

\begin{tabular}{|c|c|c|c|c|c|c|}
\hline & $\begin{array}{c}(1) \\
\text { Share }^{R}\end{array}$ & $\begin{array}{c}(2) \\
\text { Share }^{R}\end{array}$ & $\begin{array}{c}(3) \\
\text { Share }^{A}\end{array}$ & $\begin{array}{c}(4) \\
\text { Share }^{A}\end{array}$ & $\begin{array}{c}(5) \\
\text { Share }^{M}\end{array}$ & $\begin{array}{c}(6) \\
\text { Share }^{M}\end{array}$ \\
\hline time & $\begin{array}{c}-0.103^{* * *} \\
(0.012)\end{array}$ & $\begin{array}{c}-0.062^{* *} \\
(0.020)\end{array}$ & $\begin{array}{c}0.087^{* * *} \\
(0.018)\end{array}$ & $\begin{array}{c}0.047^{* *} \\
(0.020)\end{array}$ & $\begin{array}{c}0.016 \\
(0.015)\end{array}$ & $\begin{array}{c}0.016 \\
(0.015)\end{array}$ \\
\hline $\mathrm{GR} \times$ time & & $\begin{array}{c}-0.332^{* * *} \\
(0.058)\end{array}$ & & $\begin{array}{l}0.272^{* *} \\
(0.092)\end{array}$ & & $\begin{array}{c}0.060 \\
(0.063)\end{array}$ \\
\hline Between GR and SDC $\times$ time & & $\begin{array}{l}-0.061 \\
(0.035)\end{array}$ & & $\begin{array}{c}0.045 \\
(0.056)\end{array}$ & & $\begin{array}{c}0.016 \\
(0.029)\end{array}$ \\
\hline $\mathrm{SDC} \times$ time & & $\begin{array}{c}-0.128^{* *} \\
(0.049)\end{array}$ & & $\begin{array}{c}0.091 \\
(0.054)\end{array}$ & & $\begin{array}{c}0.037 \\
(0.034)\end{array}$ \\
\hline After SDC $\times$ time & & $\begin{array}{c}0.048 \\
(0.030)\end{array}$ & & $\begin{array}{c}0.003 \\
(0.028)\end{array}$ & & $\begin{array}{r}-0.051^{* *} \\
(0.017)\end{array}$ \\
\hline Observations & 748 & 748 & 748 & 748 & 748 & 748 \\
\hline$R^{2}$ & 0.764 & 0.813 & 0.565 & 0.588 & 0.070 & 0.118 \\
\hline Country FE & Yes & Yes & Yes & Yes & Yes & Yes \\
\hline Controls & No & No & No & No & No & No \\
\hline
\end{tabular}

Note: Standard errors in parentheses, clustered at country-level. The unit of observation in column (1) and (2) is the share of routine employment, i.e. clerical, craft, plant employment. The unit of observation in column (3) and (4) is the share of abstract employment, i.e. managers, professionals, technical and associate professionals, armed force employment. The unit of observation in column (5) and (6) is the share of manual employment, i.e. elementary, skilled agricultural, forestry, fishery, sales and service employment. The variable time is the number of quarters. GR is a country-specific dummy variable taking value one for periods in which a country is experiencing the Great Recession. Between GR and SDC is a country-specific dummy variable taking vale one for periods in which a country is in between the GR and the Sovereign Debt Crisis. SDC is a country-specific dummy variable taking vale one for periods in which a country is experiencing the Sovereign Debt Crisis. After SDC is a country-specific dummy taking value one for periods after the Sovereign Debt Crisis. $*, * *, * * *$ indicate significance at $90 \%, 95 \%$ and $99 \%$ level.

seasonal fluctuations, the abstract share follows a clear upward trend whereas the manual share looks more stationary. This is confirmed also in column (3) and (5) of Table 1 where we perform the same analysis of equation (1), but now with the abstract (Share ${ }^{A}$ ) and manual share $\left(\right.$ Share $\left.^{M}\right)$ as dependent variables. We see that, across all countries, the long-run fall in the routine share is almost entirely compensated by an expansion of the abstract share. When looking at the decomposition of this trend across different business cycle phases, we find that abstract share increases by $0.047 \mathrm{pp}$ every quarter in pre-recession periods (column (4)). When the EMU11 enters the GR, this positive trend accelerates by 5 times before going back to the pre-GR trend from there afterward. On the other hand, in pre-GR periods, the share of manual employment is stationary (column (6)), and neither the GR nor the SDC significantly affect this behavior. Only in periods after the SDC, the share of manual jobs starts to significantly decline by $0.05 \mathrm{pp}$ each quarter. 


\section{The Slope of the Phillips Curve and the Occupa- tional Composition of the Labor Market}

Fig. 3. The Slope of the Phillips Curve and Employment Composition

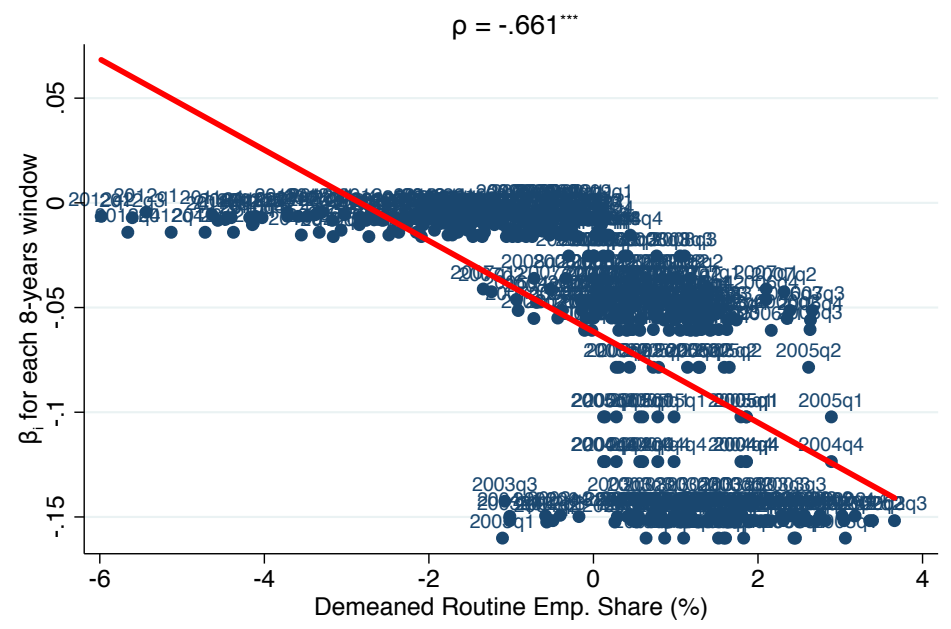

Note: This figure plots the coefficients of the Phillips Curve for each country -estimated over 8-year rolling windows- on the (demeaned) routine employment share as observed at the beginning of each 8-years window. The sample is composed of those countries that joined the EMU before 2002 (Luxembourg excluded). The equation used to estimate the slope of the Phillips curve in each window and country is $\Delta \log (p)_{i, t}=\alpha_{i}+\beta u_{i, t-1}+X_{i, t-1}^{\prime} \gamma+\epsilon_{i, t}$, where $\Delta \log (p)_{i, t}$ is the year-on-year log-change of the harmonized consumer price index (energy and food excluded) in country $i ; \alpha_{i}$ is the country fixed-effect; $u_{i, t-1}$ is the unemployment gap measured as deviation of the unemployment series from a linear trend; $X_{i, t-1}^{\prime}$ is a vector of controls including lagged inflation, past expectations on current inflation, the change in the import price index, and a dummy for each country-specific business cycle phase; $\epsilon_{i, t}$ is the error term. On top of the graph, the correlation $(\rho)$ between variables is reported along with its significance level. *, **, *** indicate significance at $90 \%, 95 \%$ and $99 \%$ level.

Does employment composition matter for the relationship between price dynamics and unemployment? Figure 3 combines the slopes of the Phillips Curve -estimated for each country and each 8-years window- with the share of routine employment (in deviation from the country specific mean) observed at the beginning of each 8-years window. This simple crossectional evidence suggests a strong negative relationships - significant at $99 \%$ levelbetween the slope of the Phillips curve and the (demeaned) routine employment share. In words, when a country is relatively richer of routine jobs, the slope of the PC will be steeper. Conversely, when a country is relatively scarcer of routine jobs, the slope of the PC will be flatter.

Clearly, this evidence cannot tell us anything related to the causal relationship between employment composition and the slope of the PC, as it is exposed to several sources of endogeneity. First of all, as discussed in Section 2.2, job polarization follows a long-run trend such that there might be a spurious correlation between the gradual decline in routine employment and the gradual flattening of the PC over time. Second, there are other long-run 
factors which might have influenced the slope of the PC, such as changes in the sectorial composition of the economy, demography, etc.

In light of this, we need a strategy to assess correctly whether employment composition is important for the relationship between prices and unemployment. In particular, we need to find a variation of the occupational composition which is ex-ante orthogonal (i) to past country specific characteristics and (ii) to past price dynamics.

\subsection{Cyclical Occupational Shifts}

In this section we provide evidence that cyclical movements in job polarization are not driven by ex-ante country characteristics, but only by the recession and its severity.

As we know from section 2.2, recessions operate on the long-run trend of job-polarization through (level) shifts in the occupational composition of the labor market. This translates into a bigger destruction of routine jobs in favor of non-routine ones (most of all abstract jobs) during recessions. To quantify these structural shifts occurred within each country, we consider the change in the level of the routine employment share matured during each recession. In other words, the extent to which the composition of the labor market of country $i$ changed due to the cycle $c=\{G R, S D C\}$ can be measured as the percentage change of the routine employment share between the peak and trough of the recession $c$, according to the business cycle dates specific to country $i$. Formally:

$$
\text { Shift }_{i, c}^{R}=\frac{\text { Share }_{\text {peak }}^{R}-\text { Share }_{\text {trough }_{i, c}}^{R}}{\text { Share }_{\text {peak } k_{i, c}}^{R}} .
$$

Figure 4 plots the levels of our measure of occupational shift $\left(S h i f t_{i, t}^{R}\right)$ for each country of the EMU11 and each recession. Despite that all countries were following the same job polarization trend (as shown in Section 2.2), the cyclical rate of routine job destruction varies substantially across EMU11 members and across recessions. The mean occupational shift is $4.6 \%$ (4.4\% for the GR and $4.8 \%$ for the SDC). The correlation between the shifts matured during the two recessions is 0.15 and it is not significantly different from zero.

Yet, it is important to test whether the heterogeneity in $S h i f t_{i, c}$ observed across countries and recessions is due to pre-recession country-specific characteristics. In fact, as shown in Autor et al. (2013), the exposure of the labor market to a "polarization shock" can be explained by the employment composition of that market before the downturn. In light of this, we look at the correlation between the routine employment share-measured one quarter before the beginning of the recession- and our measure of occupational shift. As from Figure $5(\mathrm{a})$, we find only a mild correlation not significantly different from zero. Once checked that 
Fig. 4. Occupational Shifts across EMU11 countries, by recession

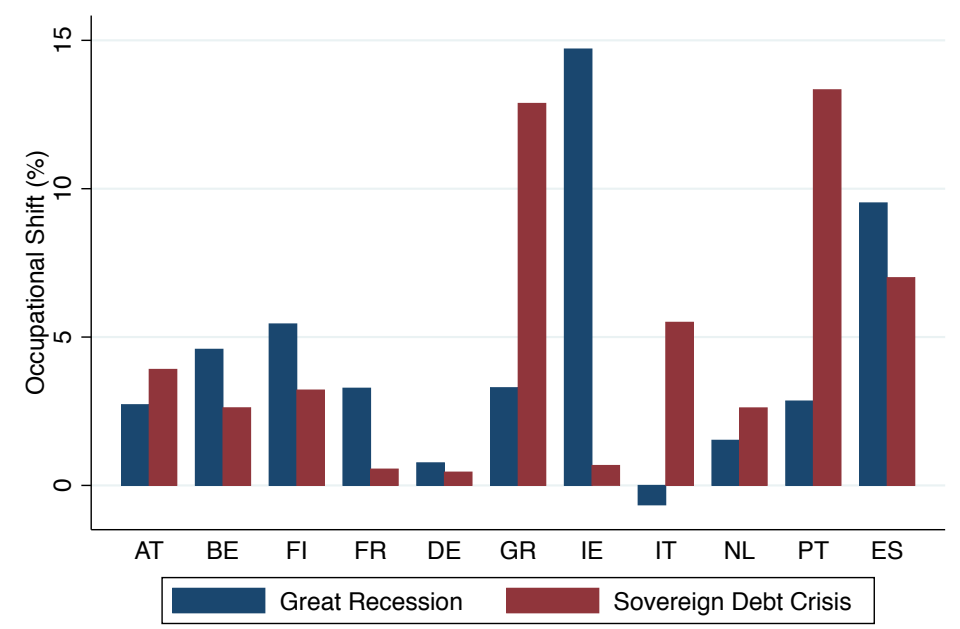

Note: This figure plots the occupational shifts experienced by each country that joined the EMU before 2002 (Luxembourg excluded) during the Great Recession and the Sovereign Debt Crisis. Each occupational shift is defined as the percentage change in routine employment share between the peak and trough of each recession, according to country-specific business cycle dates (details on the construction of the measure can be found in Section 3.1).

the pre-recession employment composition does not matter, in Figure 5(b) we check if the pace at which each economy has polarized until the start of each recession matters for the size of the cyclical occupational shift. This is mostly to control if the polarization trend is not explaining the size of the shift. Again we find a correlation not significantly different from zero. This confirms that the cyclical occupational shifts are heterogeneous across countries and recession and they are not path-dependent.

Since the occupational composition varies also across sectors in the economy (e.g. manufacturing and construction have a larger share of routine workers), we study whether the sectorial composition could be related to the cyclical shift. To do so, in Figure 5(c) we plot the share of value added from manufacturing and construction, measured one quarter before the beginning of the recession, on the shift. Once again we do not find any significant correlation. Finally, we check if pre-recession inflation dynamics correlates with the shift. Figure 5(d) show no significant relationship between pre-recession inflation and our measure of occupational shift.

In light of this, we conclude that the extent to which a country destroyed routine jobs during the two crisis is not predetermined. In other words, the rate of routine job destruction does not depend on ex-ante country-specific labor and product market characteristics and inflation dynamics.

It is now important to show that the variation in the occupational shift is really imputable to the economic downturn only. As shown in Figure 6(a), our measure of occupational shift 
Fig. 5. Pre-recession Characteristics vs. Occupational Shift

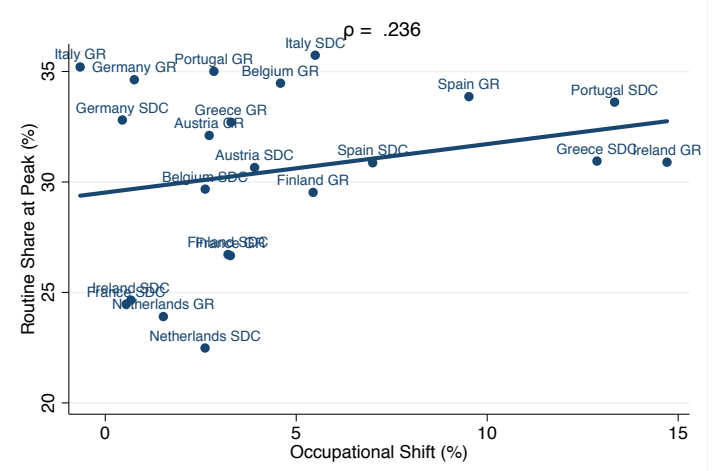

(a) Pre-recession Routine Emp.

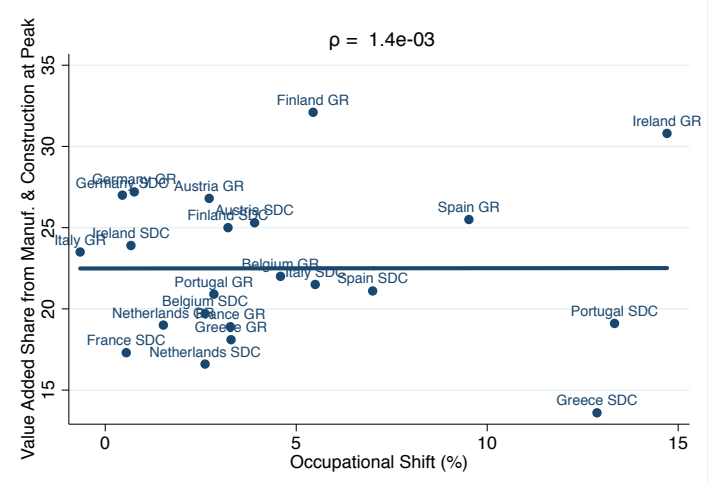

(c) Pre-recession Sectorial Composition

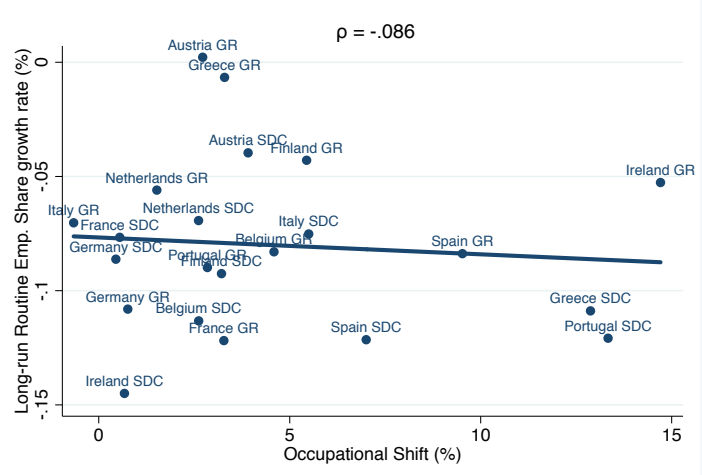

(b) Pre-recession Routine Emp. Growth

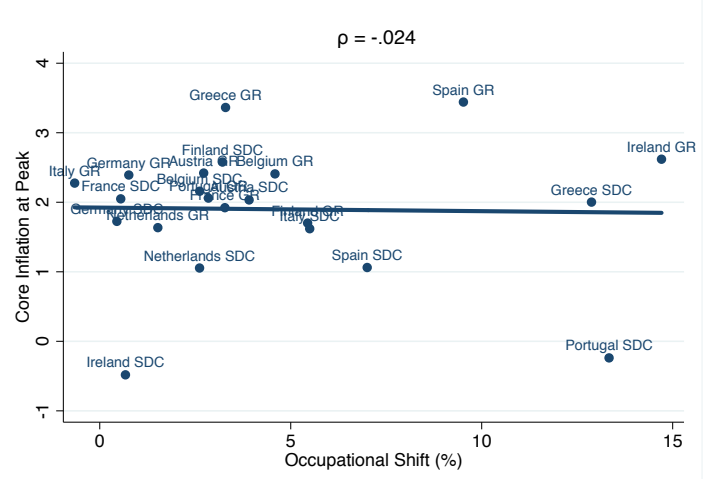

(d) Pre-recession Inflation

Note: Figure 5(a) plots the level of the routine employment share -measured at the peak of the Great Recession (GR) and Sovereign Debt Crisis (SDC)- on the occupational shift experienced during both downturns by each country that joined the EMU before 2002 (Luxembourg excluded). Figure 5(b), the y-axis is the long-run growth rate of the routine employment share, measured as the slope of the linear trend fitting the routine share series until the GR and SDC respectively. For figure 5(c), the $\mathrm{y}$-axis is the value added from manufacturing and construction (as percentage of GDP), measured at the peak of the GR and SDC. For figure 5(d), the y-axis is the level of core inflation, measured at the peak of the GR and SDC. Each occupational shift is defined as the percentage change in routine employment share between the peak and trough of each recession, according to country-specific business cycle dates. On top of each graph, the correlation $(\rho)$ between variables is reported along with its significance level. $*, * *, * * *$ indicate significance at $90 \%, 95 \%$ and $99 \%$ level.

is significantly correlated at the $99 \%$ level with the percentage change in GDP matured between the peak and trough of each recession. Similarly, Figure 6(b) displays a strong correlation -significant at 99\% level- between the duration of each downturn (expressed in quarters) and our measure of occupational shift.

This evidence suggests that the labor market transformation experienced by each country during each recession is orthogonal to country-specific characteristics, but its magnitude depends on the size and persistency of the downturn. This is true independently on the nature of the recession (i.e. GR - a financial crisis- and the SDC - a confidence crisis) and not affected by the fact that the two recessions are close in time. 
Fig. 6. Duration and Size of the Recession vs. Occupational Shift

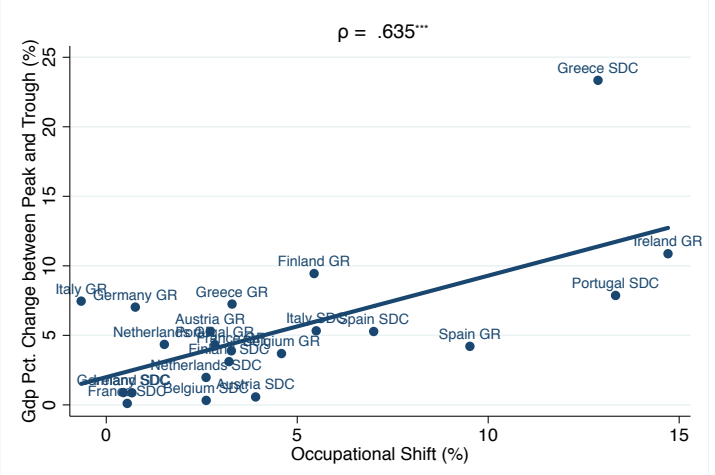

(a) GDP Contraction

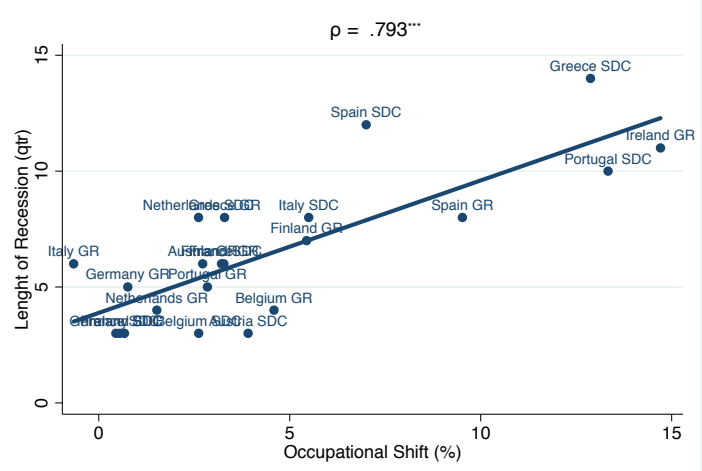

(b) Recession Duration

Note: Figure 6(a) plots the GDP percentage change -measured between the peak and trough of the Great Recession (GR) and Sovereign Debt Crisis (SDC)- on the occupational shift experienced during both downturns by each country that joined the EMU before 2002 (Luxembourg excluded). For figure 6(b), the y-axis is duration (in quarters) of each recession, measured as the number of quarters between peak and trough. Each occupational shift is defined as the percentage change in routine employment share between the peak and trough of each recession, according to country-specific business cycle dates. On top of each graph, the correlation $(\rho)$ between variables is reported along with its significance level. *, **, *** indicate significance at $90 \%, 95 \%$ and $99 \%$ level.

\subsection{Sectorial Dynamics behind Job Polarization}

Although Figure 6(c) tells us the that the sectorial composition does not matter ex-ante for the cyclical shift in the occupational structure of the labor market, we know that some specific sectors are much more concentrated of routine workers and more cyclical. This is particularly true for the manufacturing and construction sector. Figure 7(a) plots the cross-country employment share in manufacturing and construction. Clearly, the sectorial employment dynamic mimics the routine employment share dynamic of Figure 1(b). This implies that -although job polarization remains a fact across all sectors- its long-run and cyclical behavior is intertwined with manufacturing and construction.

This rises a red flag, in particular for the implication that specific sectorial dynamics can have on both price dynamics and employment composition. In other words, sectorial dynamics could be confounding factors when trying to address the role of occupational composition on the slope of the PC. Therefore, it is convenient to analyze how the sectorial structure of EMU11 countries has evolved over time and over the cycle. As shown in Figure 7(b), the contribution of manufacturing and construction (in terms of value added) has moved across countries roughly from $25 \%$ to $20 \%$ over the entire sample. This trend has accelerated in both recessions. Given this, we build a measure of sectorial shift isomorphic to equation (3): 
Fig. 7. Manufacturing and Construction Employment and Relative Weight in the Economy

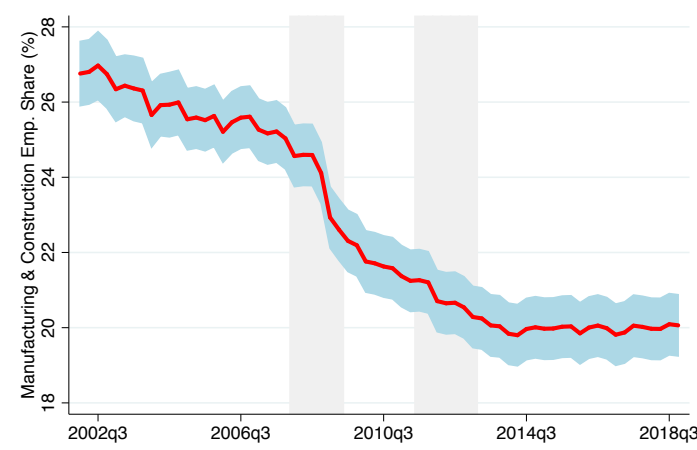

(a) Manuf. \& Construction Emp. Share

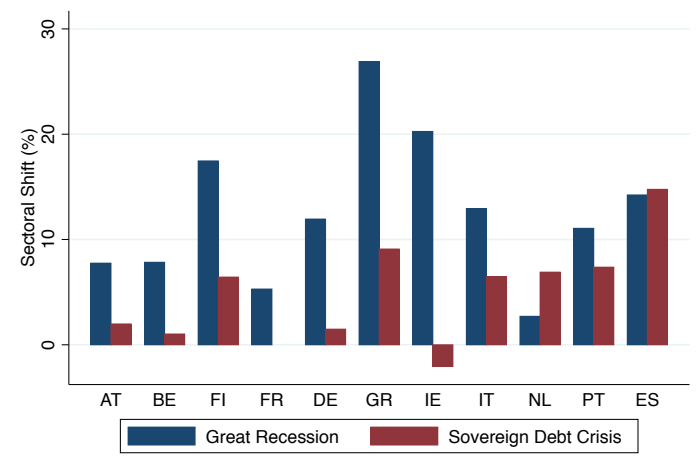

(c) Sectorial Shifts

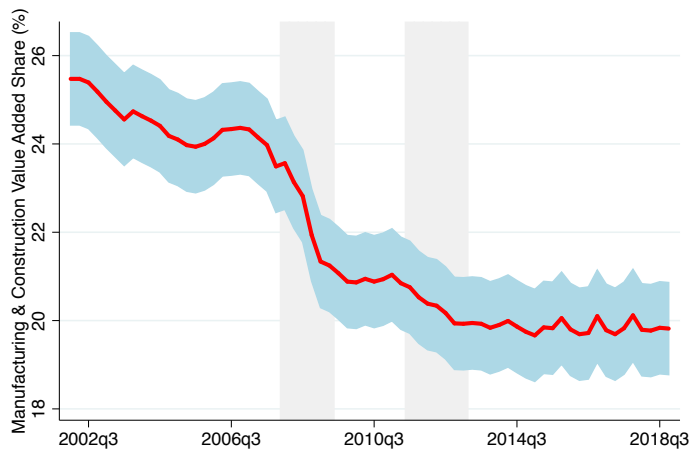

(b) Manuf. \& Construction Share of Value Added

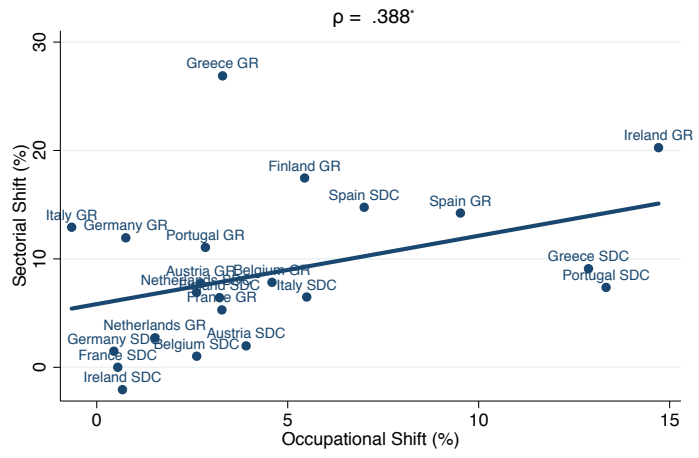

(d) Sectorial vs. Occupational Shifts

Note: Figure 7(a) plots the evolution of the mean employment share in manufacturing and construction across those countries that joined the EMU before 2002 (Luxembourg excluded). Figure 7 (b) plots the evolution of the mean share of value added from manufacturing and construction across the same 11 EMU countries. The light-blue-shaded area represents the $95 \%$ confidence interval. The two grey-shaded areas indicate respectively the periods of the Great Recession and of the Sovereign Debt Crisis as defined by the CEPR Business Cycle Committee. Data is quarterly and spans from 2002q1 to 2018q4. Figure 7(c) plots the sectorial shifts experienced by each country that joined the EMU before 2002 (Luxembourg excluded) during the Great Recession and the Sovereign Debt Crisis. Each sectorial shift is defined as the percentage change in the share of value added from manufacturing and construction measured between the peak and trough of each recession, according to country-specific business cycle dates. For Figure $7(\mathrm{~d})$, the y-axis is the sectorial and $\mathrm{x}$-axis is the occupational shift, defined as the percentage change in routine employment share measured between the peak and trough of each recession, according to country-specific business cycle dates. On top of the graph, the correlation $(\rho)$ between variables is reported along with its significance level. *, $* *, * * *$ indicate significance at $90 \%, 95 \%$ and $99 \%$ level.

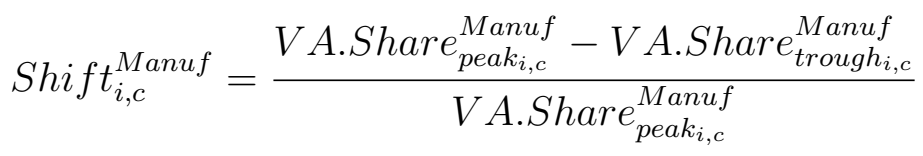

which captures the percentage change of the share of value added from manufacturing and construction in country $i$, as measured between the peak and trough of each recession $c=$ $\{G R, S D C\}$, according to the business cycle dates of country $i$. Figure 7 (c) plots the levels of our measure of sectorial shift $\left(S h i f t_{i, t}^{\text {Manuf }}\right)$ for each country of the EMU11 and each 
recession. The mean sectorial shift is $8.7 \%$ (12.6\% for the GR and $4.8 \%$ for the SDC). Finally, Figure $7(\mathrm{~d})$ plots the sectorial shift on the occupational shift. As expected, there is a positive correlation equal to 0.38 , although it is only significant the $90 \%$ level. $^{7}$ We will take this carefully in the following analysis.

\subsection{Occupational Structural Changes and the Flattening of the Price PC}

If the composition of the labor market matters for the slope of the $\mathrm{PC}$, changes in composition - orthogonal to price dynamics and country characteristics- should affect the structural relationship between prices and unemployment. In light of this argument, in this section we exploit the cross-country variation in permanent occupational shifts occurred during the GR and SDC crisis to study the flattening of the PC in periods following each recession. In order to do so, we estimate the following panel equation:

$$
\begin{aligned}
\Delta \log (p)_{i, t} & =\alpha_{i}+\beta u_{i, t-1}+X_{i, t-1}^{\prime} \gamma \\
& +\sum_{c=\{G R, S D C\}}\left\{\delta_{1, c} \text { After }_{i, c}+\beta_{c} \text { After }_{i, c} \times u_{i, t-1}\right\} \\
& +\sum_{c=\{G R, S D C\}}\left\{\delta_{2, c} \text { After }_{i, c} \times \text { Shift }_{i, c}^{R}+\tilde{\beta}_{c} \text { After }_{i, c} \times \text { Shift }_{i, c}^{R} \times u_{i, t-1}\right\} \\
& +\sum_{c=\{G R, S D C\}}\left\{\delta_{3, c} \text { After }_{i, c} \times \text { Shift }_{i, c}^{\text {Manuf }}+\tilde{\tilde{\beta}}_{c} \text { After }_{i, c} \times \text { Shift }_{i, c}^{\text {Manuf }} \times u_{i, t-1}\right\}+\varepsilon_{i, t}
\end{aligned}
$$

where $\Delta \log (p)_{i, t}$ is core inflation in country $i$ at time $t$, measured as the year-on-year logchange of the harmonized consumer price index excluding food and energy goods. ${ }^{8} \alpha_{i}$ is the country fixed-effect. $u_{i, t-1}$ is the unemployment gap measured as deviation of the unemployment series from a linear trend. ${ }^{9} X_{i, t-1}^{\prime}$ is the basic vector of controls used in the literature and it includes: lagged inflation, past expectations on current inflation, the change in the import price index. We add to this set of controls a time dummy to take into account that post-GR periods include also other business cycle phases that might affect the level of inflation. After ${ }_{i, G R}\left(\right.$ After $\left._{i, S D C}\right)$ is a dummy taking value one for periods after the GR (SDC)

\footnotetext{
${ }^{7}$ In Appendix B, we repeat the analysis of Section 2.2 and 3.1 and test if the employment share of manufacturing and construction and the value added share from these two sectors follows the cycle as the routine employment share does. Moreover, we check whether our measure of sectorial shift from equation 3.2 correlates with ex-ante country characteristics.

${ }^{8}$ See Figure A.6 for the evolution of core inflation across EMU11 countries in Appendix A.4.

${ }^{9}$ Unemployment is a stationary process for all countries but Germany for which it follows a negative trend (see Appendix A.2). For this reason, we decided to build the unemployment gap in the simplest possible way: as deviation from a linear trend. This solves the problem for Germany, and transforms the unemployment series for all other countries roughly as deviation from their mean. See Figure A.4 in Appendix A.2 for the evolution of the unemployment gap across EMU11 countries.
} 
according to country $i$ specific business-cycle dates; Shift $t_{i, G R}^{R}\left(S h i f t_{i, S D C}^{R}\right)$ is the shift in the occupational structure occurred during the GR (the SDC) as defined in equation (3) of Section 3.1. Shift $t_{i, G R}^{\text {Manuf }}\left(S h i f t_{i, S D C}^{\text {Manuf }}\right.$ ) is the shift in the sectorial structure occurred during the GR (the SDC) as defined in equation (3.2) of Section 3.2. $\varepsilon_{i, t}$ is the error term.

In words, equation (4) augments the baseline estimating equation of the price PC (i.e. the first line of the equation) by taking into account all potential structural changes occurred during each recession that might have affected both the relationship between unemployment and inflation and the level of inflation in post recession periods (i.e. the second line of the equation). On top of this, the third line of equation (4) takes into account by how much the flattening in post recession periods can be explained by structural changes in the occupational composition of the labor market occurred during each recession, once controlling contemporaneously for changes in the the sectorial composition of the economy (i.e. line four of the equation). Therefore, we will use the augmented PC of equation (4) to test whether changes in the occupational composition matter for the slope of the PC. Formally, we want to test

$$
H_{0}: \tilde{\beta}_{c}=0, \quad \forall c=\{G R, S D C\}
$$

once netting out the effect of all other possible structural changes that might have flattened the curve after the GR and the SDC. Table 2 shows results. In column (1), we start by considering the baseline PC and we include all controls. For a $1 \%$ increase in the unemployment gap, core inflation falls by $0.03 \%$. In column (2), we add the time dummy After $r_{G R}$ among the controls and we study the flattening of the PC in post-GR years by adding the interaction After $_{G R} \times u_{t-1}$. Here we find that the slope of the PC is -0.09 in pre-GR periods, but it significantly flattens and becomes equal to $-0.09+0.07=-0.02$ in post-GR periods. This indicates that some structural change has affected the relationship between unemployment and inflation after the GR. Now, we want to understand by how much such a flattening can be attributed to the occupational shift occurred during the GR. For this reason, we add the interaction After $_{G R} \times S h i f t_{G R} \times u_{t-1}$, along with After $_{G R} \times S h i f t_{G R}$ as control. As from column (3), adding these controls does not change the slope of the PC in pre-GR periods. On the other hand, the coefficient on the slope of the PC in post-GR years has now become smaller and moved from 0.07 to 0.05 . This difference is explained by cross-country variation in the occupational shift occurred during the GR. In fact, $\tilde{\beta}_{G R}$ is significantly positive meaning that countries experiencing a larger occupational shift during the GR had a flatter PC afterward. Therefore, we could conclude that -despite other potential structural changes that might have occurred during the GR and that might have influenced the relationship between unemployment and inflation- the permanent shift in the occupational structure significantly explains part of the flattening of the PC. 
Table 2: The Flattening of the Price Phillips Curve across the EMU11

\begin{tabular}{|c|c|c|c|c|c|}
\hline & $\begin{array}{c}(1) \\
\Delta \log (p)\end{array}$ & $\begin{array}{c}(2) \\
\Delta \log (p)\end{array}$ & $\begin{array}{c}(3) \\
\Delta \log (p)\end{array}$ & $\begin{array}{c}(4) \\
\Delta \log (p)\end{array}$ & $\begin{array}{c}(5) \\
\Delta \log (p)\end{array}$ \\
\hline$u_{t-1}$ & $\begin{array}{c}-0.033^{\text {*** }} \\
(0.007)\end{array}$ & $\begin{array}{c}-0.087^{* * *} \\
(0.013)\end{array}$ & $\begin{array}{c}-0.086^{* * *} \\
(0.012)\end{array}$ & $\begin{array}{c}-0.085^{* * *} \\
(0.013)\end{array}$ & $\begin{array}{c}-0.079^{* * *} \\
(0.014)\end{array}$ \\
\hline After $_{G R} \times u_{t-1}$ & & $\begin{array}{c}0.069^{* * *} \\
(0.019)\end{array}$ & $\begin{array}{l}0.052^{* *} \\
(0.018)\end{array}$ & $\begin{array}{c}0.029^{*} \\
(0.013)\end{array}$ & $\begin{array}{c}0.057^{*} \\
(0.027)\end{array}$ \\
\hline After $_{G R} \times$ Shift $_{G R}^{R} \times u_{t-1}$ & & & $\begin{array}{l}0.002^{* *} \\
(0.001)\end{array}$ & $\begin{array}{l}0.005^{* *} \\
(0.002)\end{array}$ & $\begin{array}{c}0.004^{* * *} \\
(0.001)\end{array}$ \\
\hline After $_{S D C} \times u_{t-1}$ & & & & $\begin{array}{l}-0.011 \\
(0.026)\end{array}$ & $\begin{array}{c}0.010 \\
(0.015)\end{array}$ \\
\hline After $_{G R} \times$ Shift $_{S D C}^{R} \times u_{t-1}$ & & & & $\begin{array}{l}0.010^{* *} \\
(0.005)\end{array}$ & $\begin{array}{c}0.010^{* * *} \\
(0.003)\end{array}$ \\
\hline After $_{G R} \times S h i f t_{G R}^{\text {Manuf }} \times u_{t-1}$ & & & & & $\begin{array}{c}-0.002^{* *} \\
(0.001)\end{array}$ \\
\hline After $_{S D C} \times$ Shift $_{S D C}^{\text {Manuf }} \times u_{t-1}$ & & & & & $\begin{array}{c}-0.030^{* * *} \\
(0.009)\end{array}$ \\
\hline Observations & 748 & 748 & 748 & 748 & 748 \\
\hline$R^{2}$ & 0.893 & 0.896 & 0.897 & 0.898 & 0.900 \\
\hline Country FE & Yes & Yes & Yes & Yes & Yes \\
\hline Controls & Yes & Yes & Yes & Yes & Yes \\
\hline
\end{tabular}

Note: Standard errors in parentheses, clustered at country-level. The unit of observation is inflation, measured as the year-on-year log-change of the harmonized consumer price index (energy and food excluded). After GR $\left(\right.$ After $\left._{S D C}\right)$ is dummy taking value one for periods after the GR (SDC) according to country-specific business-cycle dates; Shift ${ }_{G R}^{R}$ $\left(\right.$ Shift $\left.t_{S D C}^{R}\right)$ is the shift in the occupational structure occurred during recession GR (SDC), i.e. the percentage change in the routine employment share between the peak and trough of the recession according to country-specific business cycle dates; Shift $t_{G R}^{\text {Manuf }}$ (Shift $\operatorname{SDC}_{S D \text { f }}^{\text {Manu }}$ ) is the shift in the share of value added from manufacturing and construction occurred during recession GR (SDC), i.e. the percentage change in the share of value added from these two sectors between the peak and trough of the recession according to country-specific business cycle dates; $u_{t-1}$ is the unemployment gap measured as deviation of the unemployment series from a linear trend; the vector of controls includes lagged inflation, past expectations on current inflation, the change in the import price index, and a dummy for each country-specific business cycle phase. The sample is composed of all countries that joined the EMU before 2002 (Luxembourg excluded). Data is quarterly. *, **, *** indicate significance at $90 \%, 95 \%$ and $99 \%$ level.

Since all countries in the sample experienced also the SDC, the flattening could not be entirely due to the occupational shift occurred during the GR, but also due to the shift occurred during the SDC or other potential structural breaks happened during that downturn. We address this issue in column (4), where we add the interaction After $_{S D C} \times$ Shift $_{S D C} \times u_{t-1}$. For the same reasoning as before, we control for any other structural break that might ex- 
plain the flattening in post-SDC periods $\left(\right.$ After $\left._{S D C} \times u_{t-1}\right)$ and check whether any potential structural break in the post-post SDC years $\left(\right.$ After $\left._{S D C}\right)$ and the occupational shift occurred in that recession $\left(\right.$ After $_{S D C} \times$ Shift $\left._{S D C}\right)$ have a direct effect on the level of inflation afterward. Under this specification, we find that permanent occupational shift occurred during each recession plays a role in explaining the post-recession flattening of the PC. In detail, for the same level of unemployment gap, a $1 \%$ shift in the occupational structure occurred during the GR flattens the PC by 0.005 just after the GR. However, the PC flattens out even further in countries where there was a bigger shift in the occupational structure during the SDC. In particular, $1 \%$ occupational shift occurred during the SDC leads to a further flattening of the PC by 0.01 .

Yet, this result is exposed to omitted variable bias. In fact, as explained in Section 3.2, for our sample of countries the process of polarization goes hand in hand with the change in sectorial compositions. In fact, the role of manufacturing and construction in all EMU11 economies is decreasing, and both the GR and the SDC seems to have contributed to this. Therefore, our results could be bias due to the fact that the change in sectorial composition might not only influence inflation dynamics, but also the disappearance of routine jobs. In light of this argument, in column (5) we augment the PC with the variable After $_{i, c} \times$ Shift $_{i, c}^{\text {Manuf }}$ and After $_{i, c} \times S h i f t_{i, c}^{\text {Manuf }} \times u_{i, t-1}$ to control respectively for the effect of the sectorial shifts matured in each recession $c=\{G R, S D C\}$ on the level of inflation and on the relationship between unemployment and inflation in periods after each recession c. Notably, both $\tilde{\beta}_{G R}$ and $\tilde{\beta}_{S D C}$ are robust to this control. The only major change is for the estimates of $\beta_{G R}$, now closer to what found in column (2) and (3). As shown in Appendix $\mathrm{D}$, these results are robust to several definitions of price inflation, unemployment gap, and are not driven by sub-set of EMU11 countries.

In light of this, we can reject $H_{0}$ for all $c=\{G R, S D C\}$, and state that the structural change occurred in the labor market during the last two recessions had a role in the recent flattening of the PC. By how much? Now, we can back up the aggregate contribution of both occupational shifts on the flattening through a back-of-the-envelope calculation. By simply using our estimates from column 5 , we can say that the occupational shifts can jointly explain $\left(\tilde{\beta}_{G R}+\tilde{\beta}_{S D C}\right) / \beta_{G R}=25 \%$ of the overall flattening of the Phillips Curve from the end of the GR onward. 


\subsection{Any implication for the Wage PC?}

So far, our entire analysis has focused exclusively on the price PC, and Section 3.3 provides evidence that the occupational change in the labor market (at the net of sectorial changes and other structural breaks) has an effect of its slope. Now, we want to check if the same holds true when looking at the wage PC. We start by inspecting the evolution of the slope of the wage PC across EMU11 countries. As shown in Figure 8, the slope of the wage PC has significantly steepened (and not flattened) in the EMU11 between 2002 and 2018.

Fig. 8. The Behavior of the Wage Phillips Curve

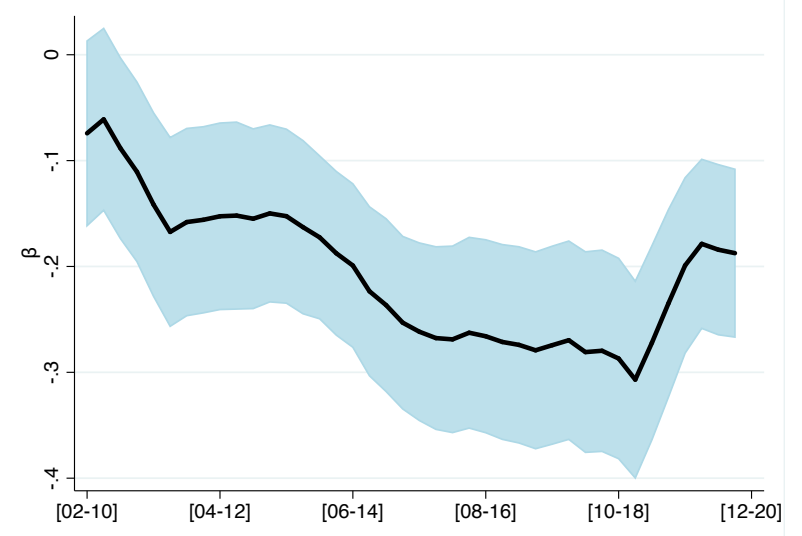

Note: Figure 8 plots the coefficient of the wage Phillips Curve estimated over 8-year rolling windows for those countries that joined the EMU before 2002 (Luxembourg excluded). The estimating equation for each window is $\Delta \log (w)_{i, t}=\alpha_{i}+\beta u_{i, t-1}+$ $X_{i, t-1}^{\prime} \gamma+\epsilon_{i, t}$, where $\Delta \log (w)_{i, t}$ is the year-on-year log-change of the business economy labor-cost index (salary and wages) in country $i ; \alpha_{i}$ is the country fixed-effect; $u_{i, t-1}$ is the unemployment gap measured as deviation of the unemployment series from a linear trend; $X_{i, t-1}^{\prime}$ is a vector of controls including a 4-quarter moving average of past wage inflation, and a dummy for each country-specific business cycle phase; $\epsilon_{i, t}$ is the error term. The light-blue-shaded area represents the $95 \%$ confidence interval. Data is at quarterly frequency.

In light of this, now we want to investigate if also this change in the slope of the wage $\mathrm{PC}$ can be related to shifts in the occupational composition of the labor market. To do so we consider again equation 4 , but with wage inflation $\left(\Delta \log (w)_{i, t}\right)$ as dependent variable. The wage inflation is build as the year-on-year log-change of the labor cost index (wages and salaries) available on Eurostat for the business economy. Here, the controls are slightly different from before. Since we do not have any measure of expectations on future wage inflation, we just control for the moving average of wage inflation in the previous four quarters. Moreover, we do not consider changes in the import price index. Table 3 shows results. As from column (1), we find that the slope of the wage PC in pre-GR periods is -0.10 , but it is not significantly different from zero. On the other hand, in all post-GR periods, the slope steepens significantly and is -0.38 . However, such steepening does not exacerbate even further after the SDC, and cannot be explained by the cross-country shifts in occupational 
Table 3: The Behavior of the Wage Phillips Curve across the EMU11

\begin{tabular}{|c|c|c|}
\hline & $\begin{array}{c}(1) \\
\Delta \log (w)\end{array}$ & $\begin{array}{c}(2) \\
\Delta \log (w)\end{array}$ \\
\hline$u_{t-1}$ & $\begin{array}{l}-0.101 \\
(0.057)\end{array}$ & $\begin{array}{l}-0.024 \\
(0.066)\end{array}$ \\
\hline After $_{G R} \times u_{t-1}$ & $\begin{array}{c}-0.375^{* *} \\
(0.140)\end{array}$ & $\begin{array}{c}0.143 \\
(0.082)\end{array}$ \\
\hline After $_{G R} \times$ Shift $_{G R}^{R} \times u_{t-1}$ & $\begin{array}{c}0.025 \\
(0.014)\end{array}$ & $\begin{array}{c}0.030 \\
(0.015)\end{array}$ \\
\hline After $_{S D C} \times u_{t-1}$ & $\begin{array}{l}0.015 \\
(0.100)\end{array}$ & $\begin{array}{l}-0.093 \\
(0.064)\end{array}$ \\
\hline After $_{S D C} \times$ Shift ${ }_{S D C}^{R} \times u_{t-1}$ & $\begin{array}{l}-0.005 \\
(0.034)\end{array}$ & $\begin{array}{l}-0.003 \\
(0.028)\end{array}$ \\
\hline After $_{G R} \times S h i f t_{G R}^{\text {Manuf }} \times u_{t-1}$ & & $\begin{array}{c}-0.025^{* *} \\
(0.007)\end{array}$ \\
\hline After $_{S D C} \times$ Shift $_{S D C}^{M a n u f} \times u_{t-1}$ & & $\begin{array}{c}0.029 \\
(0.031)\end{array}$ \\
\hline Observations & 680 & 680 \\
\hline$R^{2}$ & 0.520 & 0.541 \\
\hline Country FE & Yes & Yes \\
\hline Controls & Yes & Yes \\
\hline
\end{tabular}

Note: Standard errors in parentheses, clustered at country-level. The unit of observation is wage inflation, measured as the year-on-year log-change of the labor-cost index (salary and wages) for the business economy. After GR $_{\text {(After }}$ (ADC) is dummy taking value one for periods after the GR (SDC) according to country-specific business-cycle dates; Shift $t_{G R}^{R}$ $\left(\right.$ Shift $\left.t_{S D C}^{R}\right)$ is the shift in the occupational structure occurred during recession GR (SDC), i.e. the percentage change in the routine employment share between the peak and trough of the recession according to country-specific business cycle dates; Shift ${ }_{G R}^{\text {Manuf }}\left(\right.$ Shift $_{S D C}^{M a n u f}$ ) is the shift in the share of value added from manufacturing and construction occurred during recession GR (SDC), i.e. the percentage change in the share of value added from these two sectors between the peak and trough of the recession according to country-specific business cycle dates; $u_{t-1}$ is the unemployment gap measured as deviation of the unemployment series from a linear trend; the vector of controls includes past expectations on current wage inflation (measured as a four quarters moving average), and a dummy for each country-specific business cycle phase. The sample is composed of all countries that joined the EMU before 2002 (Luxembourg excluded). Data is quarterly. *,**, *** indicate significance at $90 \%, 95 \%$ and $99 \%$ level.

composition occurred during both crisis. Hence we conclude that the change in slope of the wage PC cannot be related directly to occupational dynamics and composition. Then, what can explain the steepening? In column (2), we control for the sectorial changes occurred during both recessions, and we find that the steepening is actually due to the change in the sectorial composition occurred during the GR. In other words, the more the sectorial composition of a country moved away from manufacture and construction, the more the relationship between wage growth and unemployment gap is stronger in post-GR periods. As shown in Appendix D.2, these results are robust to several definitions of wage inflation, 
unemployment gap, and are (most often) not driven by sub-set of EMU11 countries.

To sum up, it is the decline in manufacture and construction -rather than employment composition- that can explain the steepening of the wage PC. We therefore focus on the price PC.

\section{Theoretical Framework and Micro-foundation}

Why does job-polarization flattens the price Phillips Curve? We now move to the theoretical analysis with three main objectives. First, to show that labor market characteristics matter for the slope of the price PC. Second, to illustrate how changing the composition of the labor market (for a given level of equilibrium unemployment) can flatten the price PC through an increase in labor market fluidity. Third, to provide micro-evidence on how job polarization increased the fluidity while keeping other structural parameters, and unemployment, unchanged.

\subsection{The model}

We first set up an analytical New Keynesian model with unemployment and search and matching frictions, following Blanchard and Galí (2010). ${ }^{10}$ There is a continuum of members in a representative household that consumes a differentiated basket of imperfectly substitutable goods, supplies labor $0 \leq N_{t} \leq 1$, and discounts the future at rate $\beta$. The household maximises the following expected utility:

$$
E_{0} \sum \beta^{t}\left(\log C_{t}-\chi \frac{N_{t}^{1+\phi}}{1+\phi}\right)
$$

where $C_{t}=\left(\int_{0}^{1} C_{t}(z)^{\frac{\varepsilon-1}{\varepsilon}} d z\right)^{\frac{\varepsilon}{\varepsilon-1}}$ and $\phi$ is the inverse Frisch labor supply elasticity. There is a continuum of firms $i \in[0,1]$ producing a differentiated final good $Y_{t}(i)$ :

$$
Y_{t}(i)=X_{t}(i)
$$

where $X_{t}(i)$ is the quantity of the intermediate good bought by firm $i$ from the large number of identically and perfectly competitive intermediate firm producers $j \in[0,1]$. Intermediate firms produce the homogeneous good $X$ with a linear production function $X_{t}(j)=A_{t} N_{t}$, where $A_{t}$ is an exogenous process depicting technology. Employment decisions are taken by the intermediate firm $j$ and are described by the following labor demand accumulation

\footnotetext{
${ }^{10}$ We refer to the original paper for more details.
} 
equation:

$$
N_{t}(j)=(1-\delta) N_{t-1}(j)+H_{t}(j) .
$$

$\delta \in(0,1)$, a crucial parameter for our analysis, determines the exogenous separation rate and $H_{t}(j)$ measures the workers hired in period $t$. $\delta$ can be interpreted as the fraction of workers that had a job at $t-1$ but are not working anylonger at the beginning of period $t$ and need to find a job. $\delta N_{t-1}$ will therefore be the increase in the stock of people unemployed between period $t-1$ and $t$. This drives the necessity to define two "types" of unemployment: $U_{t}$, ex-ante unemployment (i.e. unemployment at the beginning of the period) and $u_{t}$, expost unemployment (i.e. unemployment, after hiring, at the end of period $t$ ). Therefore $U_{t}=u_{t-1}+\delta N_{t-1}$.

As long as our parametrization guarantees that the benefit from an extra hour of work is higher than its marginal rate of substitution at full employment (i.e. $W_{t}>\chi C_{t}$ ), then the labor market is characterized by full participation. This condition implies that $u_{t}=1-N_{t}$ and $U_{t}=1-(1-\delta) N_{t-1}$. As a consequence, the flow of newly hired workers in period $t$ can be rewritten as $H_{t}=\int_{0}^{1} H_{t}(j) d j=N_{t}-(1-\delta) N_{t-1}$.

We now define labor market tightness $x_{t}$ (or job finding rate). This measures the ratio of aggregate hires to unemployment $x_{t}=\frac{H_{t}}{U_{t}} \in[0,1]$, capturing the probability of being hired in period $t$. Hiring is costly and the cost is a positive function of market tightness and vacancies are filled any time the hiring cost is paid:

$$
G_{t}=A_{t} B x_{t}^{\alpha}
$$

with $\alpha \geq 0$ and $B>0$, where $B$ is the parameter governing matching efficiency.

We also follow Blanchard and Galí (2010) to introduce real wage rigidities in a simple manner, assuming a wage schedule of the form:

$$
\left.W_{t}=\left[\frac{1}{\mu}-(1-\beta(1-\delta))\right) B x^{\alpha} A^{\gamma}\right] A_{t}^{1-\gamma}=\Theta A_{t}^{1-\gamma}
$$

This implies that when $\gamma=0$ our wage will correspond to Nash bargaining, while when $\gamma=1$ we will have rigid wages, as in Hall (2005). $\mu$ is the gross desired markup of the final good producer.

To complete the model, we need to introduce final firm's price setting behavior. Price are rigid and follow Calvo (1983) pricing formulation: each period the final good producer has probability $(1-\theta)$ to reset prices, while the remaining producers $\theta$ keep their prices 
unchanged. The optimal price setting rule turns to be the standard

$$
E_{t}\left\{\sum_{k=0}^{\infty} \theta^{k} Q_{t, t+k} Y_{t+k, t}\left(P_{t}^{*}-\mu P_{t+k} M C_{t+k}\right)\right\}=0
$$

where $P_{t}=\left[(1-\theta)\left(P_{t}^{*}\right)^{1-\varepsilon}+\theta\left(P_{t-1}\right)^{1-\varepsilon}\right]^{\frac{1}{1-\varepsilon}} \cdot P_{t}^{*}$ denotes the price picked by the firm able to reset prices, $Y_{t+k, t}$ is the level of output in period $t+k$ for a firm last able to reset prices in period $t, Q_{t . t+k}$ is the stochastic discount factor common across all households $\equiv \beta^{k} \frac{C_{t}}{C_{t+k}} \frac{P_{t}}{P_{t+k}}$, and finally $M C_{t+k}$ is the real marginal cost. The latter is given by the relative prices of intermediate good producers $P_{t}^{I}=M C_{t}^{n}$, given the assumption of perfect competition, and the aggregate consumption price level $P_{t}$ :

$$
\begin{aligned}
M C_{t}=\frac{P_{t}^{I}}{P_{t}}= & W_{t}+G_{t}-\beta(1-\delta) E_{t}\left\{\frac{C_{t}}{C_{t+1}} G_{t+1}\right\} \\
& =\Theta A_{t}^{1-\gamma}+B x_{t}^{\alpha}-\beta(1-\delta) E_{t}\left\{\frac{C_{t}}{C_{t+1}} B x_{t+1}^{\alpha}\right\} .
\end{aligned}
$$

In this formulation of the marginal cost function lies the crucial difference with respect to the standard NK model. It is immediate to see how labor market frictions and the real wage rigidity appear and affect the marginal cost function.

\subsection{The Price Phillips Curve}

To derive some of our results analytically, we focus on the relationship between inflation and unemployment, the NK Phillips Curve, in log-deviations from a zero inflation steady state (denoted with lower case letters with a hat): ${ }^{11}$

$$
\pi_{t}=\beta E_{t}\left\{\pi_{t+1}\right\}-\kappa_{0} \hat{u}_{t}+\kappa_{L} \hat{u}_{t-1}+\kappa_{F} E_{t}\left\{\hat{u}_{t+1}\right\}-\lambda \Phi \gamma \hat{a}_{t}
$$

where

$$
\begin{aligned}
& \lambda=\frac{(1-\beta \theta)(1-\theta)}{\theta} \\
& \Phi \equiv \frac{\mu W}{A}=1-(1-\beta(1-\delta)) g \mu \\
& \kappa_{0} \equiv \frac{\lambda h_{0}}{(1-u)}, \quad \kappa_{L} \equiv \frac{-\lambda h_{L}}{(1-u)}, \quad \kappa_{F} \equiv-\frac{\lambda h_{F}}{(1-u)}
\end{aligned}
$$

\footnotetext{
${ }^{11}$ See Appendix C for a full derivation.
} 


$$
\begin{aligned}
h_{0} & \equiv\left(\frac{\alpha g \mu}{\delta}\right)\left(1+\beta(1-\delta)^{2}(1-x)\right)+\beta(1-\delta) g \mu\left(\xi_{1}-\xi_{0}\right) \\
h_{L} & \equiv-\left(\frac{\alpha g \mu}{\delta}\right)(1-\delta)(1-x)-\beta(1-\delta) g \mu \xi_{1} \\
h_{F} & \equiv-\beta(1-\delta) g \mu\left(\frac{\alpha}{\delta}-\xi_{0}\right) \\
\xi_{0} & \equiv \frac{1-g(1+\alpha)}{(1-\delta g)}, \quad \xi_{1} \equiv \frac{g(1-\delta)(1+\alpha(1-x))}{(1-\delta g)} .
\end{aligned}
$$

What comes out clearly from this formulation, is that the slope of the price Phillips Curve, $\kappa_{0}$, depends on labor market characteristics. In particular on the separation rate, $\delta$, market tightness $x$ and on the curvature of the cost function $\alpha$.

Before analyzing the characteristics of this formulation in details, we derive a simplified version of it. As in Blanchard and Galí (2010), we assume that both hiring cost with respect to output $g$ and the separation rate $\delta$ are small. These assumptions allow to rewrite an approximated Phillips curve simply as:

$$
\widehat{\pi}_{t}=\kappa \widehat{u}_{t}+\kappa(1-\delta)(1-x) \widehat{u}_{t-1}-\Psi \gamma \widehat{a}_{t}
$$

where

$$
\kappa \equiv-\frac{\alpha g \mu \lambda}{\delta(1-u)} \quad \text { and } \quad \Psi \equiv \frac{\lambda \Phi}{\left(1-\beta \rho_{a}\right)}
$$

which is easy to study analytically. We start by noticing that the slope of the Phillips Curve can be written as a function of standard Calvo parameters $\lambda$, the markup $\mu$ and labor market characteristics (i.e. the level of equilibrium unemployment $(u)$, the separation rate $(\delta)$, the market tightness condition $(x)$ and the parameters of the hiring cost function $(B, \alpha))$ :

$$
\frac{\alpha g \mu \lambda}{\delta(1-u)}=\frac{\alpha B x^{\alpha} \mu \lambda}{\delta(1-u)}=\frac{\alpha B\left(\frac{H}{U}\right)^{\alpha} \mu \lambda}{\delta(1-u)}=B \mu \lambda \frac{\alpha\left(\frac{\delta N}{1-(1-\delta) N}\right)^{\alpha}}{\delta N}
$$

In order to investigate the effects of the labor market composition on the slope of the Phillips curve, first we need to take a stand on the effect of polarization on the equilibrium level of unemployment. Supported by the overall dynamic of unemployment in the European Monetary Union (Figure 9 shows that the unemployment level converged back to its prerecession level), we maintain steady state unemployment $u=1-N$ constant. $^{12}$

Let us define, as in Blanchard and Galí (2010), a fluid labor market one characterized

\footnotetext{
${ }^{12}$ This implies that every movement in the separation rate will result in an adjustment of the job finding rate to maintain constant the equilibrium level of unemployment. In particular an increase in the separation rate implies an increase in tightness $\frac{\partial x}{\partial \delta}=\frac{N(1-N)}{[1-(1-\delta) N]^{2}}>0$.
} 
Fig. 9. EMU unemployment rate

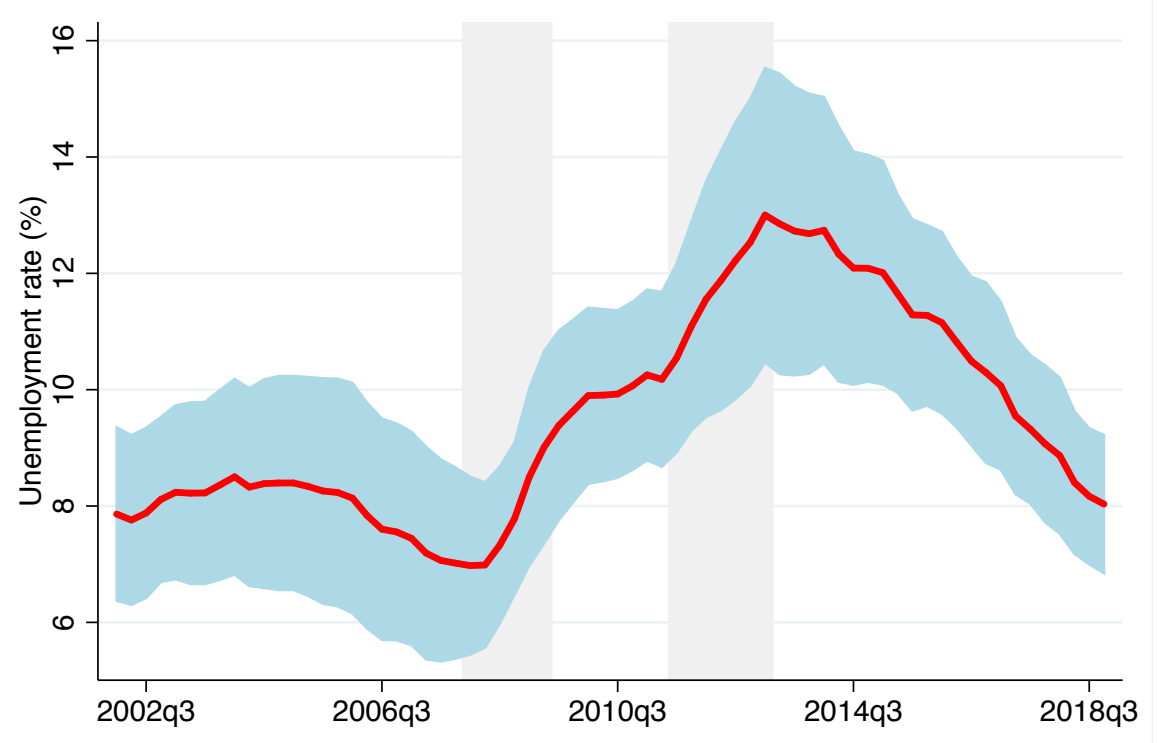

Note: This figure plots the evolution of the unemployment rate (for the labor force in the 15-74 age bracket) across those countries that joined the EMU before 2002 (Luxembourg excluded). The light-blue-shaded area represents the $95 \%$ confidence interval. The two grey-shaded areas indicate respectively the periods of the Great Recession and of the Sovereign Debt Crisis as defined by the CEPR Business Cycle Committee. Data is quarterly and spans from 2002q1 to $2018 \mathrm{q} 4$.

by high separation and high job finding rate. How does the Phillips Curve slope change in response to an increase in the fluidity of the labor market? How does an increase in the separation rate affects the slope of the Phillips Curve? We can easily show that:

$$
\frac{\partial \kappa}{\partial \delta}=\mu \lambda B \frac{\alpha(\delta N)^{(\alpha-2)} N}{(1-(1-\delta) N)^{1+\alpha}}[(\alpha-1)(1-(1-\delta) N)-\alpha \delta N]
$$

is negative when $\alpha<\frac{1-N+\delta N}{1-N}=\frac{U}{u}$. Notice that this condition is always satisfied when $\alpha<1$, an empirical (see Pissarides and Petrongolo (2001) and Barnichon and Figura (2015), among others) and theoretical regularity (Shimer (2005)). Therefore, an increase in the fluidity of the labor market results in a flattening of the Phillips Curve in the simplified model.

We now need to investigate if this result generalizes to the full extended model. We proceed with calibrating the model, considering each period a quarter. For preferences, price setting and wage rigidity we take the standard parameters used in Blanchard and Galí (2010): $\beta=0.99, \phi=1, \epsilon=6$, and $\theta=0.7457$. For the other parameters we look at evidence from the EMU. We estimate the hiring cost as a fraction of GDP to be 1.512 percent, implying a matching efficiency $B$ equal to 0.3297. The equilibrium level of unemployment is set to $8 \%$, the average value for the EMU11 in the pre-recession period. Regarding labor market 
parameters, we take a large range of possible values, considering an aggregate $\delta \in[0.05,0.3]$, implying $x \in[0.36,0.78]$, and a curvature parameter $\alpha \in[0.3,0.7]$.

Figure 10 shows the sign of the derivative of the slope of the Phillips curve for different values of $\delta$ and $\alpha$. The relationship is highly non linear but negative for most of the considered subset. The exception is when the separation rate is extremely low and $\alpha$ quite high, which are unrealistic values for these parameters. Therefore, even in the extended model, higher separation rate leads to a flatten price PC.

Fig. 10. Derivative of the Slope of the Price Phillips Curve - Full Model

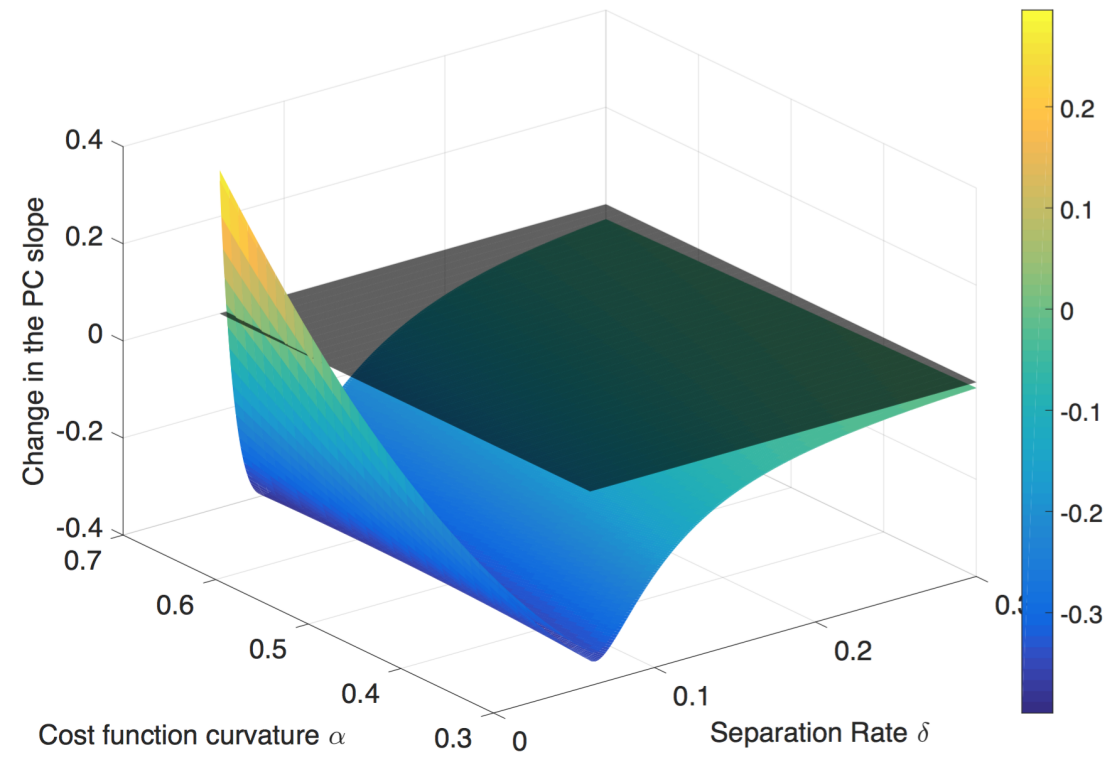

Note: This figure plots the partial derivative of the Price Phillips curve with respect to the separation rate $\frac{\partial \kappa_{0}}{\partial \delta}$, computed from equation (9), for different starting values of $\delta$, the separation rate, and $\alpha$ the curvature of the cost function.

\subsection{Labor Market Fluidity vs. Price Stickiness}

As shown in the previous section, higher separation rate $\delta$ leads to a more fluid labor market and a flattening of the PC. If job polarization affects the slope of the PC through this channel, we should observe in the data some heterogeneity in the separation rate across jobs and time. This would corroborate the idea that the transition to a more fluid labor market -through the disappearance of routine jobs- has implication for the observed flattening of the PC. In order to analyze if this is the case, first we build a measure for $\delta$ by job. In particular, in line with the methodology of Hobijn and Şahin (2009), we collect country-level (Eurostat) data on unemployment composition by duration and last occupation. In this way, we can back up the timing and size of flows from each occupation to unemployment. 
Hence, we normalize each job-specific flow from employment to unemployment by the level of aggregate employment in the previous period. Therefore, we obtain three job-specific separation rates such that their sum equates the aggregate separation rate in the economy.

Figure 11(a) shows the cross-country mean separation rate by occupation (along with 95\% confidence interval) for periods before the GR (2002-2007) and after the SDC (20142018). There are two facts to stress. First of all, before the GR, the average separation rate in the abstract market was roughly three times larger than the separation rate for the routine and manual market, and these differences are statistically significant. In other words, aggregate level of separation in the economy is mostly explained by abstract jobs. Second, since the composition of the labor market after the SDC has changed in favor of abstract jobs (see Section 2.2) and the separation rate of these occupation is higher than others, the weight of this segment of the labor market to aggregate separation must be bigger such that the aggregate separation rate should be higher as well. This is indeed what we find: in periods after the SDC, the separation rate of abstract jobs has significantly increased from $3 \%$ to $4 \%$ whereas the separation rate for routine jobs have significantly (but only slightly) declined. All of this traduces into an aggregate separation rate in post-SDC periods higher than before, moving from $5.7 \%$ to $6.4 \% .{ }^{13}$ Using the calibrated model of Section 4.2, this change in $\delta$ would imply a flattening of the PC of $14 \%$.

If this arguments points directly at labour market characteristics as plausible explanation of the flattening of the $\mathrm{PC}$, it is important to check if the traditional variable controlling price-update behavior - the Calvo parameter $\lambda$ - is somehow influenced by the composition of the labor market. In fact, we know that the process of job polarization goes hand in hand with technological adoption, automation and offshoring, which ultimately can influence pricing behavior in the product market (see for example Aghion, Antonin, Bunel and Jaravel (2020), Fujiwara and Zhu (2020), and Fueki, Maehashi et al. (2019)). For this reason, we exploit the Wage Dynamic Survey ${ }^{14}$ from the ECB to relate the frequency of final

\footnotetext{
${ }^{13} \mathrm{As}$ a theoretical consequence of higher separation rate for abstract jobs (with respect to others), the hiring rate $x$ should also be higher. In Appendix E, we show that this is the case, even if we do not find a significant increase in the aggregate hiring rate for periods after the SDC. For an unemployment rate close to pre-GR levels, this would suggests an aggregate decline of the matching efficiency parameter $B$, that instead we have assumed to be constant. An indirect way to test such deterioration in matching efficiency would be to check whether the Beveridge Curve has shifted out in recent years. We know this is the case. Latest data on the Beveridge Curve can be seen here: ec.europa.eu/eurostat/statistics-explained/index.php?title=Jobvacancy_and_unemployment_rates_-_Beveridge_curve.

${ }^{14}$ This survey was conducted in 3 ways $(2008,2009,2014)$ and asks the representative manager of a company some price-related questions. For example, if the management has recently changed prices of the final product and how many times prices where changed in a year. Moreover, the survey also asks the share of workers employed in a routine, abstract or manual occupation. Once considering only respondents to questions on both price updates and workforce composition, we end up with a sample of 3325 firms spread over 10 of the EMU11 countries considered (no data is available for Finland).
} 
Fig. 11. Mean Separation and Calvo Parameter by Occupation across EMU11

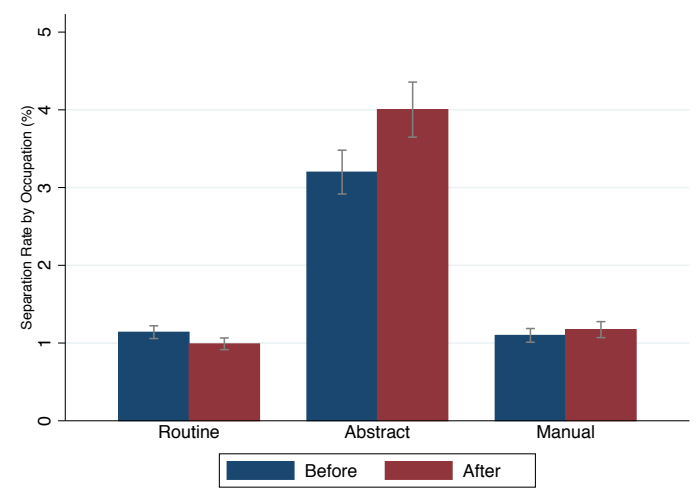

(a) Separation Rate
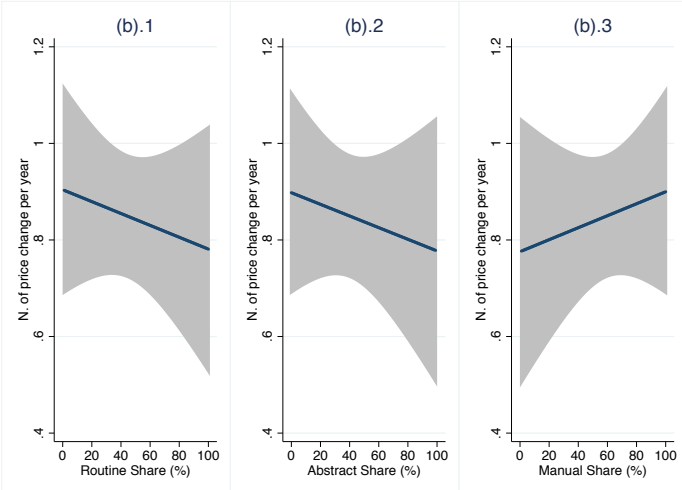

(b) Calvo Parameter

Note: Figure 11(a) plots the mean separation rate (with $95 \%$ confidence interval) by occupation (routine, abstract or manual) across countries that joined the EMU before 2002 (Luxembourg excluded). Each job-specific separation rate is build by studying the (last) job composition and duration of the unemployment pool in each year and country in order to identify correctly the timing and size of flows from each job to unemployment. Then, each job-specific flow from employment to unemployment is normalized by the level total employment in the previous period, such that the sum of the three job-specific separation rates gives the aggregate separation rate for the economy. Each cross-country mean is computed in two periods in time: before the Great Recession (between 2002 and 2007) and after the Sovereign Debt Crisis (between 2014 and 2018). Figure 11(b).1 to 11(b).3 plots the linear relationship between the number of product price updates and the occupational workforce composition at the firm level. Data comes from the three waves of the Wage Dynamics Survey of the ECB, which includes response from firms in all countries that joined the EMU before 2002. The there waves were conducted in 2008, 2009, 2014. No data is available for Finland.

good price update to the workforce composition of a sample of firms across the EMU11. Figure 11(b) plots the linear relationship (and 95\% confidence interval) between the number of price changes (per year) -as reported by the management of the firm- and the workforce job composition of the firm. In Figure 11(b).1 the share of routine workers is on the x-axis. Although the relationship is negative there is no statistical difference in the frequency of price update between firms fully composed by routine workers and firms fully composed by non-routine workers. If - on the contrary-such heterogeneity would be true, then the decline of non-routine workers in the economy should lead to lower price stickiness, higher $\lambda$ and -all else equal- a steeper slope of the PC, which is not the case in the data. We obtain similar evidence when considering the share of abstract workers on the x-axis, as in Figure 11(b).2. The relationships turns positive when considering the share of manual workers on the x-axis, as in Figure 11(b).3, but also in this case, there is no significant difference between firms rich or poor of manual workers.

All in all, this evidence proves that employment relocation from less to more fluid occupations -as triggered by the process of job polarization- is indeed an important channel to

See https://www.ecb.europa.eu/pub/economic-research/research-networks/html/researcher_wdn.en.html for more information on the survey and variables construction. 
rationalize the observed flattening of the $\mathrm{PC}$ in recent years.

\section{Conclusions}

In the last twenty years, labor markets across the European Monetary Union (EMU) have dramatically changed composition: the share of routine employment (clerical and production occupations) has shrunk in favour of abstract employment (professional, managerial occupations). At the same time, the same economies experienced a flattening of the price Phillips Curve (PC). This paper relates these two empirical facts and proves that occupational composition and heterogeneity across jobs have important implications for the structural relationship between unemployment and inflation.

We show all of this by exploiting the long-run and cyclical features of job polarization across countries. In fact, routine employment follows a downward trend, which is very homogeneous across EMU members. However, recessions -like the Great Recession (GR) and Sovereign Debt Crisis (SDC)- operates on the long-run trend of polarization through shifts. In other words, during downturns, the composition of the labor market changes dramatically with the share of routine employment rapidly shrinking in favour of abstract employment. These out-of trend occupational shifts cannot be explained by pre-recession country characteristics or inflation dynamics. On the contrary, they depend on the severity and length of the downturn within each country. Therefore, we use these exogenous shifts in employment composition to study whether countries that "polarized" more during a downturn have experienced an immediate flattening of the PC just afterward. We find that this is the case, and we estimate that the occupational shifts occurred during the GR and SDC are responsible for a fourth of the observed flattening of the PC. This result is robust also when controlling for other structural breaks that might have occurred during each crisis and that might have affected the slope of PC (e.g. the smaller role of manufacture in the economy).

What drives these results is the heterogeneity across occupations. By using the theoretical framework of Blanchard and Galí (2010), we show that an important factor for the slope of the PC is the fluidity of the labor market, i.e. the rate at which workers separate from employers and find other jobs. Hence, we prove analytically that higher fluidity leads to a flatter price PC. We back this theoretical results with further micro evidence, showing that indeed the market of abstract jobs is on average three times more fluid than the market of routine jobs, and that the overall transition of the labor market from routine to abstract occupations have increased the aggregate separation rate across EMU countries. 


\section{References}

Acemoglu, Daron (2002): Directed technical change. The Review of Economic Studies, 69(4), pp. 781-809.

Acemoglu, Daron, Philippe Aghion and Giovanni L Violante (2001): Deunionization, technical change and inequality. In: Carnegie-Rochester conference series on public policy, vol. 55, pp. 229-264. Elsevier.

Acemoglu, Daron and David Autor (2011): Skills, tasks and technologies: Implications for employment and earnings. Handbook of labor economics, 4, pp. 1043-1171.

Acemoglu, Daron and Pascual Restrepo (2017): Robots and Jobs: Evidence from US labor markets.

Açıkgöz, Omer Tugrul and Barıs Kaymak (2008): The Rising Skill Premium and Deunionization in the United States.

Aghion, Philippe, Céline Antonin, Simon Bunel and Xavier Jaravel (2020): What are the labor and product market effects of automation? New evidence from France.

Akerlof, George A, William T Dickens, George L Perry, Robert J Gordon and N Gregory Mankiw (1996): The macroeconomics of low inflation. Brookings papers on economic activity, 1996(1), pp. 1-76.

Autor, David H (2007): Technological change and earnings polarization: Implications for skill demand and economic growth. In: Massachusetts Institute for Technology, Economics Program Working Paper Series, part of the Supplemental Materials for Innovation and US Competitiveness The Conference Board report.

Autor, David H, David Dorn and Gordon H Hanson (2013): The China syndrome: Local labor market effects of import competition in the United States. The American Economic Review, 103(6), pp. 2121-2168.

Autor, David H, David Dorn and Gordon H Hanson (2015): Untangling trade and technology: Evidence from local labour markets. Economic Journal, 125(584), pp. 621-46.

Autor, David H, Lawrence F Katz and Melissa S Kearney (2006): The polarization of the US labor market. Tech. rep., National Bureau of Economic Research.

Ball, Laurence M and Sandeep Mazumder (2019): A Phillips curve for the euro area. Tech. rep., National Bureau of Economic Research. 
Barnichon, Regis and Andrew Figura (2015): Labor Market Heterogeneity and the Aggregate Matching Function. American Economic Journal: Macroeconomics, 7(4), pp. 222-249.

Benigno, Pierpaolo and Luca Antonio Ricci (2011): The inflation-output trade-off with downward wage rigidities. American Economic Review, 101(4), pp. 1436-66.

Bernanke, Ben (2007): Inflation expectations and inflation forecasting. Tech. rep., Board of Governors of the Federal Reserve System (US).

Berson, Clémence, Louis de Charsonville, Pavel Diev, Violaine Faubert, Laurent Ferrara et al. (2018): Does the Phillips curve still exist? Rue de la Banque, (56).

Blanchard, Olivier (2016): The Phillips Curve: Back to the'60s? American Economic Review, 106(5), pp. 31-34.

Blanchard, Olivier and Jordi Galí (2010): Labor Markets and Monetary Policy: A New Keynesian Model with Unemployment. American Economic Journal: Macroeconomics, 2(2), pp. $1-30$.

Bobeica, Elena and Marek Jarocinski (2017): Missing disinflation and missing inflation: the puzzles that aren't.

Bruine de Bruin, Wändi, Wilbert Vanderklaauw, Julie S Downs, Baruch Fischhoff, Giorgio Topa et al. (2010): Expectations of inflation: The role of demographic variables, expectation formation, and financial literacy. Journal of Consumer Affairs, 44(2), pp. 381-402.

Bulligan, Guido and Eliana Viviano (2017): Has the wage Phillips curve changed in the euro area? IZA Journal of Labor Policy, 6(1), pp. 1-22.

Calvo, Guillermo A. (1983): Staggered prices in a utility-maximizing framework. Journal of Monetary Economics, 12(3), pp. 383-398.

Cantore, Cristiano, Filippo Ferroni and Miguel Len-Ledesma (2020): The Missing Link: Monetary Policy and The Labor Share. Journal of the European Economic Association, 19(3), pp. 1592-1620.

Ciccarelli, Matteo, Juan A Garcia and Carlos Montes-Galdón (2017): Unconventional monetary policy and the anchoring of inflation expectations.

Ciccarelli, Matteo and Chiara Osbat (2017): Low inflation in the euro area: Causes and consequences. ECB occasional paper, (181). 
Daly, Mary C and Bart Hobijn (2014): Downward nominal wage rigidities bend the Phillips curve. Journal of Money, Credit and Banking, 46(S2), pp. 51-93.

Daly, Mary C, Bart Hobijn and Benjamin Pyle (2016): Whats up with wage growth. FRBSF Economic Letter, 7.

Del Negro, Marco, Michele Lenza, Giorgio E Primiceri and Andrea Tambalotti (2020): Whats up with the Phillips Curve? NBER Working Papers 27003, National Bureau of Economic Research, Inc.

Deroose, M, Arnoud Stevens et al. (2017): Low Inflation in the euro area: causes and consequences. Economic Review, (i), pp. 111-125.

Dinlersoz, Emin and Jeremy Greenwood (2016): The rise and fall of unions in the United States. Journal of Monetary Economics, 83, pp. 129-146.

Dovern, Jonas and Geoff Kenny (2017): The long-term distribution of expected inflation in the euro area: what has changed since the great recession?

Draghi, Mario (2015): Structural reforms, inflation and monetary policy.

Faccini, Renato and Leonardo Melosi (2020): Bad Jobs and Low Inflation. Working Paper Series WP 2020-09, Federal Reserve Bank of Chicago.

Fitzgerald, Terry J, Juan Pablo Nicolini et al. (2014): Is there a stable relationship between unemployment and future inflation?: Evidence from US cities. Citeseer.

Foster, Lucia, Cheryl Grim and John Haltiwanger (2016): Reallocation in the Great Recession: cleansing or not? Journal of Labor Economics, 34(S1), pp. S293-S331.

Fueki, Takuji, Kohei Maehashi et al. (2019): Inflation Dynamics in the Age of Robots: Evidence and Some Theory. Tech. rep., Bank of Japan.

Fujiwara, Ippei and Feng Zhu (2020): Robots and labour: implications for inflation dynamics. BIS Paper, (111c).

Gaggl, Paul and Sylvia Kaufmann (2019): The cyclical component of labor market polarization and jobless recoveries in the US. Journal of Monetary Economics.

Giannone, Domenico, Michele Lenza, Daphne Momferatou and Luca Onorante (2014): Short-term inflation projections: A Bayesian vector autoregressive approach. International journal of forecasting, 30(3), pp. 635-644. 
Goos, Maarten and Alan Manning (2007): Lousy and lovely jobs: The rising polarization of work in Britain. The review of economics and statistics, 89(1), pp. 118-133.

Guerrieri, Luca, Christopher Gust and J. David López-Salido (2010): International Competition and Inflation: A New Keynesian Perspective. American Economic Journal: Macroeconomics, 2(4), pp. 247-280.

Hall, Robert E. (2005): Employment Fluctuations with Equilibrium Wage Stickiness. American Economic Review, 95(1), pp. 50-65.

Hazell, Jonathon, Juan Herreo, Emi Nakamura and Jn Steinsson (2020): The Slope of the Phillips Curve: Evidence from U.S. States. NBER Working Papers 28005, National Bureau of Economic Research, Inc.

Hobijn, Bart and Ayşegül Şahin (2009): Job-finding and separation rates in the OECD. Economics Letters, 104(3), pp. 107-111.

Hooper, Peter, Frederic S Mishkin and Amir Sufi (2020): Prospects for inflation in a high pressure economy: Is the Phillips curve dead or is it just hibernating? Research in Economics, 74(1), pp. 26-62.

Jaimovich, Nir and Henry E Siu (2020): Job polarization and jobless recoveries. Review of Economics and Statistics, 102(1), pp. 129-147.

Jorgenson, Dale W (2001): Information technology and the US economy. American Economic Review, 91(1), pp. 1-32.

Kiley, Michael T et al. (2015): Low Inflation in the United States: A Summary of Recent Research. Tech. rep., Board of Governors of the Federal Reserve System (US).

Leduc, Sylvain, Daniel J Wilson et al. (2017): Has the wage Phillips curve gone dormant? FRBSF Economic Letter, 30, p. 16.

Mavroeidis, Sophocles, Mikkel Plagborg-Møller and James H Stock (2014): Empirical evidence on inflation expectations in the New Keynesian Phillips Curve. Journal of Economic Literature, 52(1), pp. 124-88.

McLeay, Michael and Silvana Tenreyro (2020): Optimal inflation and the identification of the Phillips curve. NBER Macroeconomics Annual, 34(1), pp. 199-255.

Mincer, Jacob and Stephan Danninger (2000): Technology, unemployment, and inflation. Tech. rep., National Bureau of Economic Research. 
Mishkin, Frederic S (2011): Monetary policy strategy: lessons from the crisis. Tech. rep., National Bureau of Economic Research.

Moretti, Laura, Luca Onorante and Shayan Zakipour-Saber (2019): Phillips curves in the euro area.

Moscarini, Giuseppe and Fabien Postel-Vinay (2017): The job ladder: Inflation vs. reallocation. Draft, Yale University.

Murphy, A (2018): The Death of the Phillips Curve? Federal Reserve Bank of Dallas. Tech. rep., Research Department, Working Paper 1801,.

Natoli, Filippo and Laura Sigalotti (2017): A new indicator of inflation expectations anchoring. Tech. rep., ECB Working Paper.

Ng, M, D Wessel and L Sheiner (2018): The Hutchins Center Explains: The Phillips Curve. Brookings Up Front (August 21).

Petrosky-Nadeau, Nicolas, Etienne Wasmer and Philippe Weil (2021): When Hosios meets Phillips: Connecting efficiency and stability to demand shocks. CEPR Discussion Papers 15833, C.E.P.R. Discussion Papers.

Pfajfar, Damjan and John M Roberts (2018): The role of expectations in changed inflation dynamics.

Pfajfar, Damjan and Emiliano Santoro (2008): Asymmetries in inflation expectation formation across demographic groups.

Pissarides, Christopher A. and Barbara Petrongolo (2001): Looking into the Black Box: A Survey of the Matching Function. Journal of Economic Literature, 39(2), pp. 390-431.

Powell, Jerome H (2018): Monetary policy and risk management at a time of low inflation and low unemployment. Business Economics, 53(4), pp. 173-183.

Ravenna, Federico and Carl E Walsh (2008): Vacancies, unemployment, and the Phillips curve. European Economic Review, 52(8), pp. 1494-1521.

Roberts, John M (2004): Monetary policy and inflation dynamics.

Schmitt-Grohé, Stephanie and Martin Uribe (2013): Downward nominal wage rigidity and the case for temporary inflation in the eurozone. Journal of Economic Perspectives, 27(3), pp. 193-212. 
Shimer, Robert (2005): The Cyclical Behavior of Equilibrium Unemployment and Vacancies. American Economic Review, 95(1), pp. 25-49.

Speck, Christian (2016): Inflation anchoring in the euro area.

Yellen, Janet L et al. (2015): Inflation Dynamics and Monetary Policy: A speech at the Philip Gamble Memorial Lecture, University of Massachusetts, Amherst, Amherst, Massachusetts, September 24, 2015. Tech. rep.

Yoon, Jong-Won, Jinill Kim and Jungjin Lee (2018): Impact of demographic changes on inflation and the macroeconomy. KDI Journal of Economic Policy, 40(1), pp. 1-30. 


\section{APPENDIX (not for publication)}

\section{Appendix A. Data}

\section{A.1. Employment Data}

Eurostat gives both information on employment shares and employment level for several countries and age-groups. We consider only time-series for Austria, Belgium, Finland, France, Germany, Greece, Ireland, Italy, Netherlands, Portugal and Spain, but not for Luxembourg since this has several points in the series defined as unreliable by the Eurostat itself. Occupations are coded according to International 2008 Standard Classification of Occupations 2008 (ISCO-08) in 14 groups. We consider employment series for workers in the 15-74 age bracket. Unfortunately, there is a statistical break in the employment-occupation series in 2011q1 due to changes in occupation classification and definition. We correct for this such that employment shares still sum to one and the aggregate unemployment rate does not change in the period of the reclassification. Hence, we follow Jaimovich and Siu (2020) and group these 14 jobs in three major categories based on their task-content. Hence, we define (i) managers, professionals, technical and associate professionals, armed force employees as abstract workers; (ii) clerical, craft and plant employees as routine workers; (iii) elementary, skilled agricultural, forestry and fishery employees, sales and service workers as manual workers. Under this grouping, we finally build employment shares series for each major category. Figure Figure A.3, A.2 and A.3 plots employment shares for each occupation and country, for periods between 2002q1 and 2018q4.

\section{A.2. Unemployment Data}

Eurostat provides quarterly series of the unemployment rate for population in the 15-74 age bracket by country. Hence, we consider data for Austria, Belgium, Finland, France, Germany, Greece, Ireland, Italy, Netherlands, Portugal and Spain. Figure A.4 plot the unemployment rate for each country between 2002q1 and 2018q4.

\section{A.3. Country-specific Business Cycle Dates}

Typically, a recession is defined as a time-window for which GDP falls for at least two consecutive quarters. According to this, the peak of a recession is the date before the GDP contraction begins and the trough is the is the last date for which GDP growth rate is still negative. In this paper, we slightly depart from this standard definition. As usual, we define 
Fig. A.1. Routine Employment Share by EMU11 country
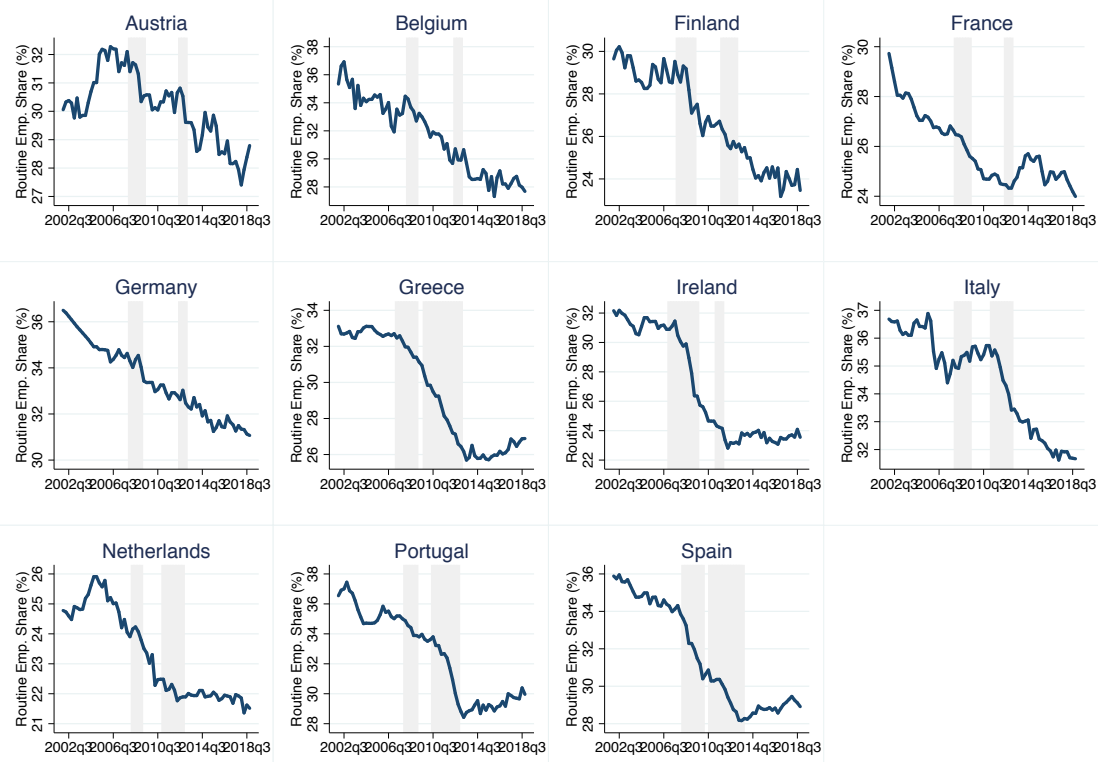

Note: The figure plots the routine employment share for each country that joined the EMU before 2002 (Luxembourg excluded). The routine employment share is defined as the sum of employment in clerical, craft a plant occupations over total employment. Data is at quarterly frequency and comes from EUROSTAT. The two grey-shaded areas indicate respectively the periods of the Great Recession (GR) and of the Sovereign Debt Crisis (SDC) specific to each country.

Fig. A.2. Abstract Employment Share by EMU11 country
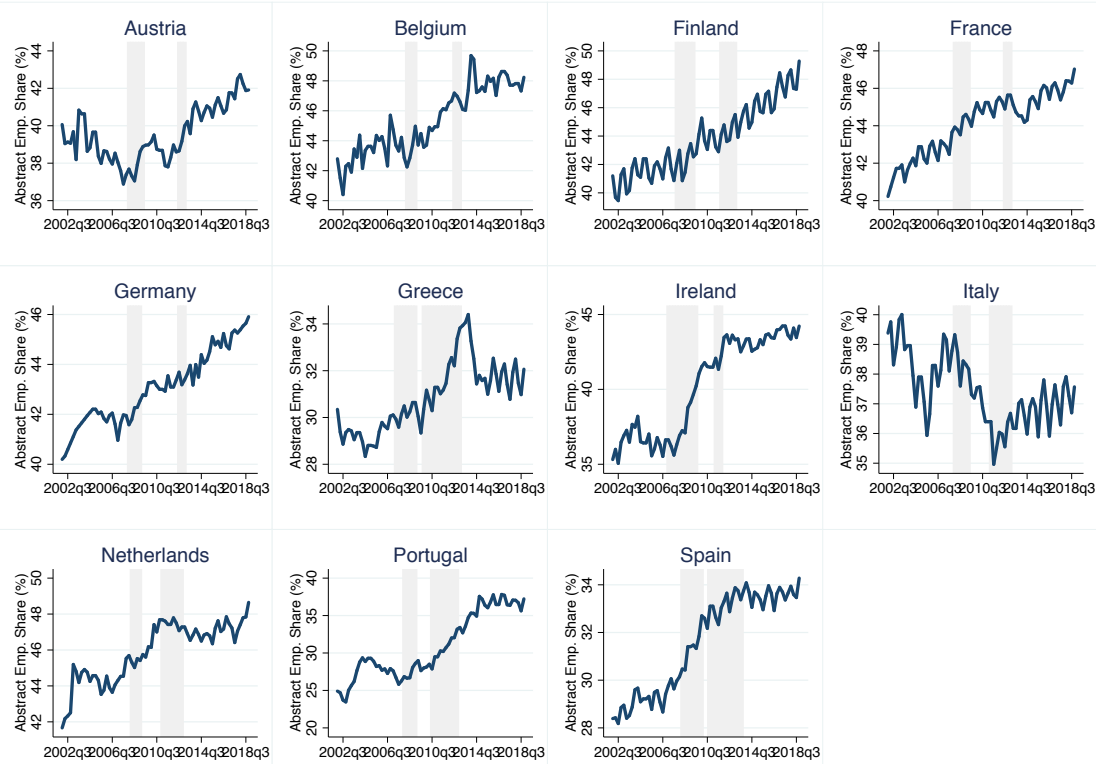

Note: The figure plots the abstract employment share for each country that joined the EMU before 2002 (Luxembourg excluded). The abstract employment share is defined as the sum of employment in managerial, professional, technical and associate professional, and armed force occupations over total employment. Data is at quarterly frequency and comes from EUROSTAT. The two grey-shaded areas indicate respectively the periods of the Great Recession (GR) and of the Sovereign Debt Crisis (SDC) specific to each country. 
Fig. A.3. Manual Employment Share by EMU11 country
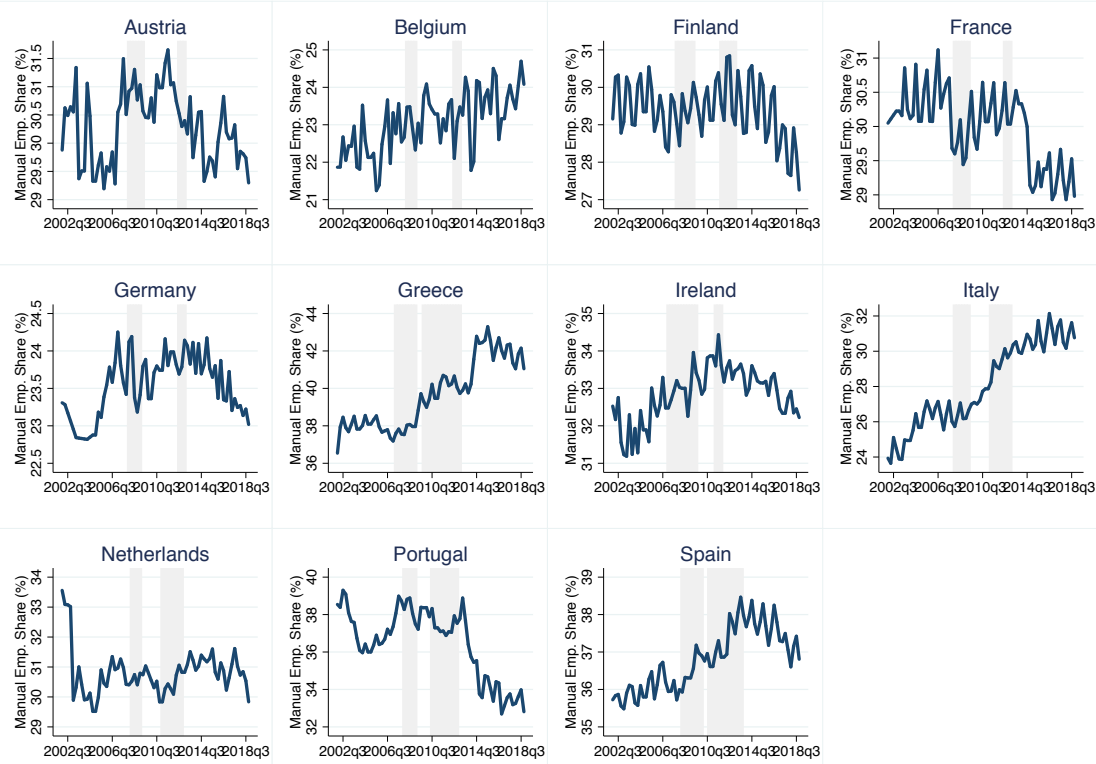

Note: The figure plots the manual employment share for each country that joined the EMU before 2002 (Luxembourg excluded). The routine employment share is defined as the sum of employment in skilled agricultural, forestry and fishery occupations, and sales and service occupations over total employment. Data is at quarterly frequency and comes from EUROSTAT. The two grey-shaded areas indicate respectively the periods of the Great Recession (GR) and of the Sovereign Debt Crisis (SDC) specific to each country.

Fig. A.4. Unemployment Rate by EMU11 country
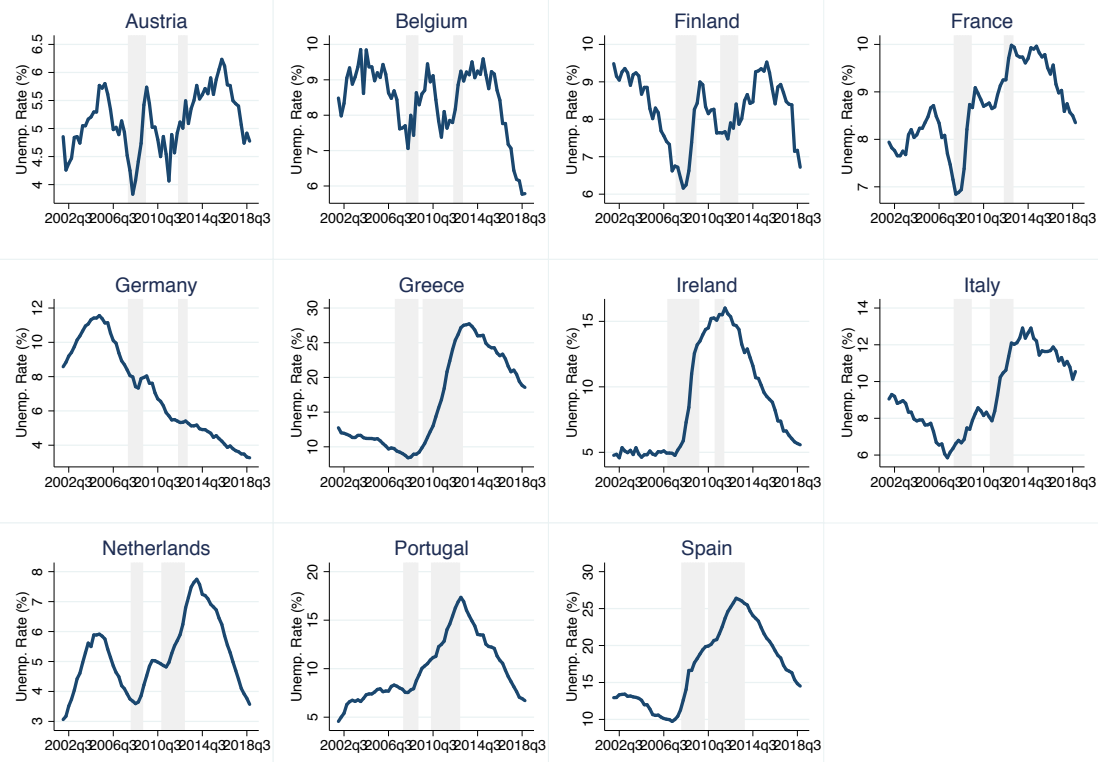

Note: The figure plots the unemployment rate for each country that joined the EMU before 2002 (Luxembourg excluded). Data is at quarterly frequency and comes from EUROSTAT. The two grey-shaded areas indicate respectively the periods of the Great Recession (GR) and of the Sovereign Debt Crisis (SDC) specific to each country. 
as a recession a period in which GDP falls for at least two consecutive quarters such that the peak of the recession is identified as the last quarter before which real GDP starts falling. However, we define the trough of the recession as the last quarter after which real GDP starts increasing again for at least two consecutive quarters. In case of two consecutive recessions, this definition is more convenient than the standard one because (i) it allows us to consider as a unique recession two consecutive GDP contractions when distanced only by one quarter of GDP expansion, (ii) and therefore to exclude minor changes in the business cycle phase. Table A.1 reports business cycle dates backed-up according to our definition.

Table A.1: Business Cycle Dates for EMU11 countries

\begin{tabular}{lccc}
\hline \hline COUNTRY & & Great Recession & Sovereign Debt Crisis \\
\hline Austria & peak & $2008 \mathrm{q} 1$ & $2012 \mathrm{q} 3$ \\
\hline & trough & $2009 \mathrm{q} 2$ & $2013 \mathrm{q} 1$ \\
\hline Belgium & peak & $2008 \mathrm{q} 2$ & $2012 \mathrm{q} 3$ \\
\hline & trough & $2009 \mathrm{q} 1$ & $2013 \mathrm{q} 1$ \\
\hline Finland & peak & $2007 \mathrm{q} 4$ & $2011 \mathrm{q} 4$ \\
\hline & trough & $2009 \mathrm{q} 2$ & $2013 \mathrm{q} 1$ \\
\hline France & peak & $2008 \mathrm{q} 1$ & $2012 \mathrm{q} 3$ \\
\hline & trough & $2009 \mathrm{q} 2$ & $2013 \mathrm{q} 1$ \\
\hline Germany & peak & $2008 \mathrm{q} 1$ & $2012 \mathrm{q} 3$ \\
\hline & trough & $2009 \mathrm{q} 1$ & $2013 \mathrm{q} 1$ \\
\hline Greece & peak & $2007 \mathrm{q} 2$ & $2009 \mathrm{q} 4$ \\
\hline & trough & $2009 \mathrm{q} 1$ & $2013 \mathrm{q} 1$ \\
\hline Ireland & peak & $2007 \mathrm{q} 1$ & $2011 \mathrm{q} 2$ \\
\hline & trough & $2009 \mathrm{q} 3$ & $2011 \mathrm{q} 4$ \\
\hline Italy & peak & $2008 \mathrm{q} 1$ & $2011 \mathrm{q} 2$ \\
\hline \multicolumn{5}{c}{ Netherlands } & peak & $2009 \mathrm{q} 2$ & $2013 \mathrm{q} 1$ \\
\hline \multicolumn{5}{c}{ peagh } & $2008 \mathrm{q} 2$ & $2011 \mathrm{q} 1$ \\
\hline Portugal & peak & $2009 \mathrm{q} 1$ & $2012 \mathrm{q} 4$ \\
\hline \multicolumn{5}{c}{ Spain } & trough & $2008 \mathrm{q} 1$ & $2010 \mathrm{q} 3$ \\
\hline & peak & $2009 \mathrm{q} 1$ & $2012 \mathrm{q} 4$ \\
\hline \hline & trough & $2008 \mathrm{q} 2$ & $2010 \mathrm{q} 4$ \\
\hline
\end{tabular}

\section{A.4. Core Inflation Data}

From the ECB Data Warehouse we collect information on prices and expected inflation. In particular, we use the Harmonized Consumer Price Index (excluded energy and food) to build year-on-year inflation rate at quarterly frequency. Figure A.6 plots core inflation for 
Fig. A.5. GDP Growth Rate by EMU11 country
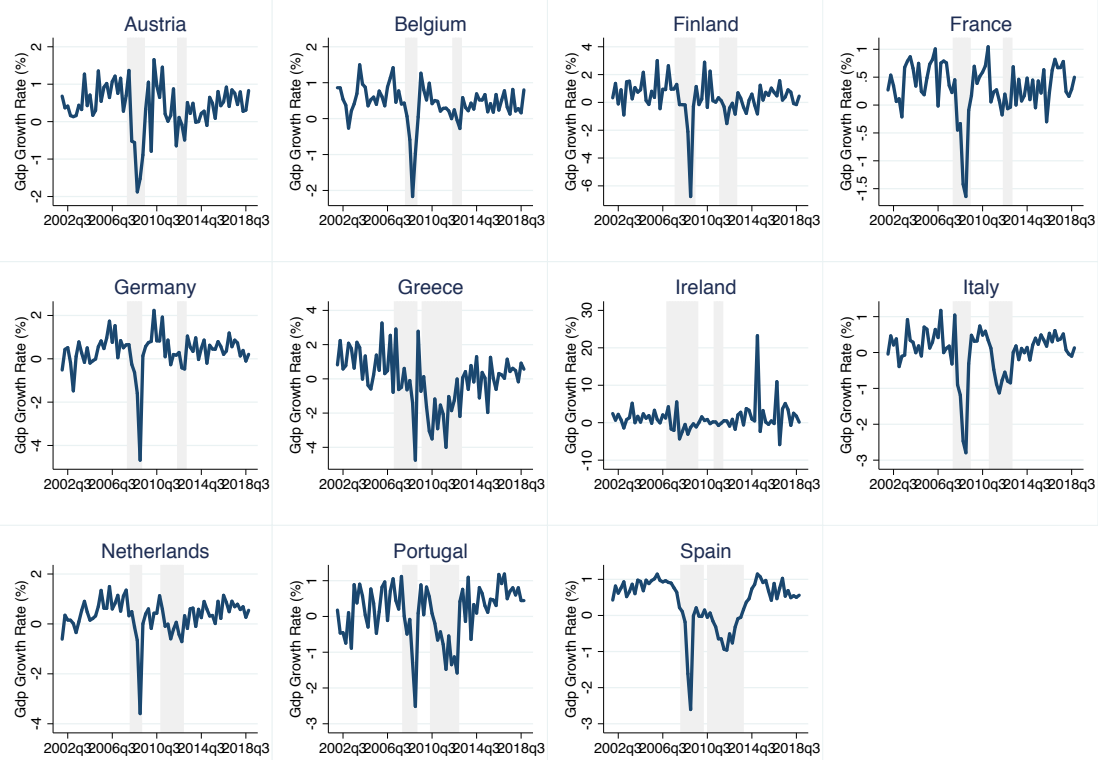

Note: The figure Gdp growth rate for each country. Data is at quarterly frequency and comes from EUROSTAT. The two grey-shaded areas indicate respectively the periods of the Great Recession (GR) and of the Sovereign Debt Crisis (SDC) specific to each country.

Fig. A.6. Core Inflation by EMU11 country
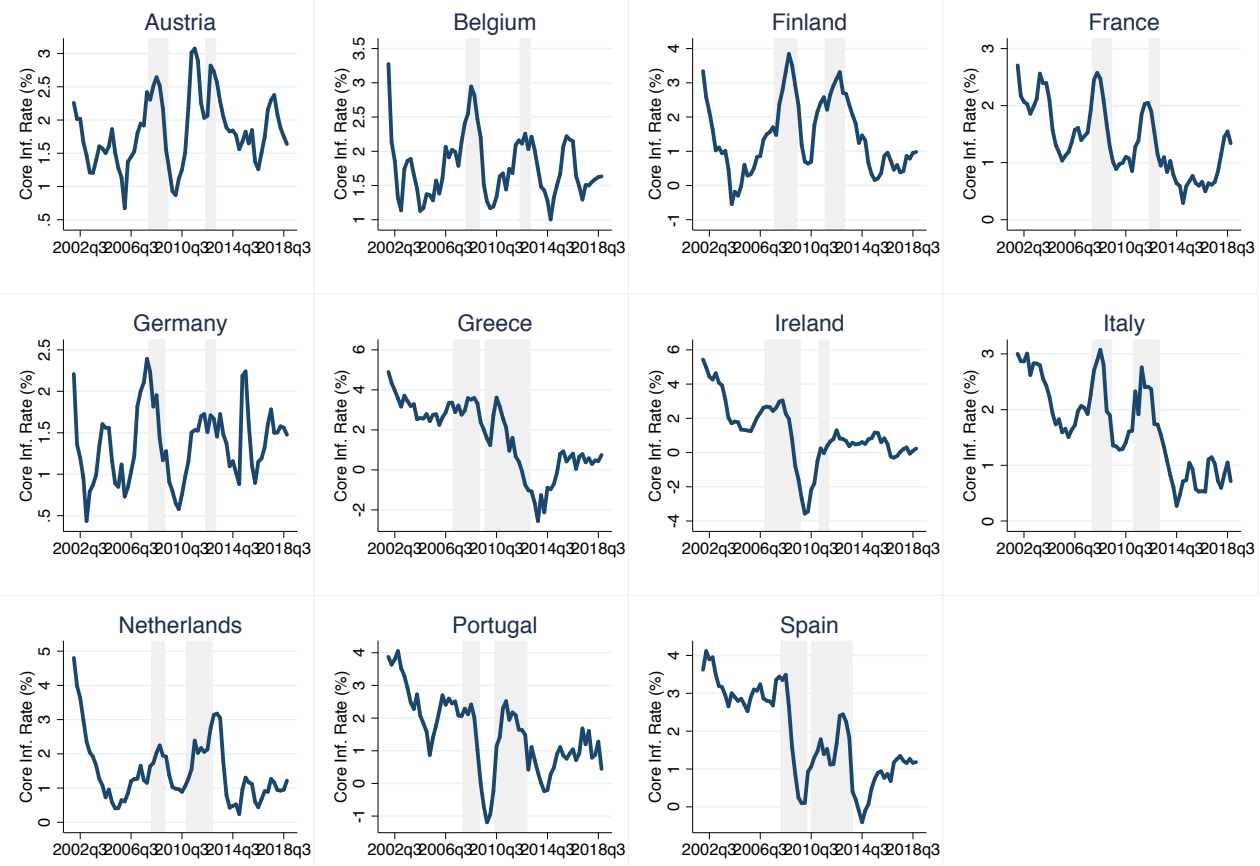

Note: The figure plots the year-on-year core inflation rate (food and energy excluded) for each country that joined the EMU before 2002 (Luxembourg excluded). Data is at quarterly frequency and comes from the ECB Data Warehouse. The two greyshaded areas indicate respectively the periods of the Great Recession (GR) and of the Sovereign Debt Crisis (SDC) specific to each country. 
Austria, Belgium, Finland, France, Germany, Greece, Ireland, Italy, Netherlands, Portugal and Spain.

\section{Appendix B. The Role of Manufacturing and Construc- tion}

\section{B.1. Trend Decomposition}

Consider the time series of the share of manufacturing and construction employment and the time series of the share of value added from these two sectors. How do these series behave in the long-run and over the cycle? To answer this question, we repropose the analysis of Section 2.2:

$$
Y_{i, t}=\alpha_{i}+\beta_{1} \text { time }+\beta_{2} \text { phase }_{i, t}+\beta_{3} \text { phase }_{i, t} \times \text { time }+\epsilon_{i, t}
$$

where $\alpha_{i}$ is the country fixed effect, time is the number of quarters, $\epsilon_{i, t}$ is the error term and phase $_{i}=$ [Before GR, GR, Between GR and SDC, SDC, After SDC] is a vector of mutually exclusive dummies taking value one if, at time $t$, country $i$ is currently in that cyclical phase. The phase $_{i}$ time-dummy is country specific, i.e. we use country specific business cycle dates to define the beginning and the end of each recession, as explained in Section 2.1. $Y_{i, t}$ is either the manufacturing and construction employment share or the share of value added from the same two sectors. Table B.1 shows results. As from column (1), the employment share in manufacturing and construction has been following a negative trend in the period 2002q1-2018q4. In column (2), we decompose this trend and find that the GR has actually accelerated it. In between the GR and SDC, the decline of this employment share was not significantly different from the pre-GR trend. Although the coefficient of the interaction term is negative, the SDC did not affect significantly the trend of manufacturing and construction employment. On the other way around, in post-SDC periods the slope of the trend changes with respect to pre-GR periods. In particular, in post-SDC periods the share of manufacturing and construction employment is basically stable.

We find a similar pattern when considering the share of value added from manufacturing and construction as dependent variable. As shown in column (3), the share of value added in these two sectors is declining over time. When we decompose this trend for each phase of the business cycle, we find that the GR has dramatically accelerated the pre-GR trend. In between the GR and SDC, the decline of the value added share in not significantly different from pre-GR periods. Although the coefficient on the interaction term is negative, the SDC does not significantly affect the trend. Conversely, after the SDC, the decline in the share of 
value added from manufacturing and construction stops.

All in all, this evidence suggests that also the share of employment and value added in manufacturing and construction follows a negative trend (at least until the end of the SDC) and the cycle. However, differently from the behavior of the routine employment share described in Section 2.2, only the GR significantly accelerates the process of destruction of manufacturing and construction jobs and the reorganization of the economy away from these two sectors.

Table B.1: Trend Decomposition of Manufacturing and Construction Employment Share and Value Added across the EMU11

\begin{tabular}{|c|c|c|c|c|}
\hline & $\begin{array}{c}(1) \\
\text { Share }^{\text {Manuf }} \\
\end{array}$ & $\begin{array}{c}(2) \\
\text { Share }^{\text {Manuf }} \\
\end{array}$ & $\begin{array}{c}(3) \\
\text { VA.Share } \\
\text { Manuf }\end{array}$ & $\begin{array}{c}(4) \\
\text { VA.Share }\end{array}$ \\
\hline time & $\begin{array}{c}-0.127^{* * *} \\
(0.017)\end{array}$ & $\begin{array}{c}-0.085^{* * *} \\
(0.018)\end{array}$ & $\begin{array}{c}-0.100^{* * *} \\
(0.024)\end{array}$ & $\begin{array}{l}-0.070^{*} \\
(0.033)\end{array}$ \\
\hline $\mathrm{GR} \times$ time & & $\begin{array}{c}-0.438^{* * *} \\
(0.065)\end{array}$ & & $\begin{array}{c}-0.388^{* * *} \\
(0.096)\end{array}$ \\
\hline Between GR and SDC $\times$ time & & $\begin{array}{c}0.021 \\
(0.051)\end{array}$ & & $\begin{array}{c}0.119 \\
(0.066)\end{array}$ \\
\hline $\mathrm{SDC} \times$ time & & $\begin{array}{l}-0.105 \\
(0.095)\end{array}$ & & $\begin{array}{l}-0.063 \\
(0.069)\end{array}$ \\
\hline After SDC $\times$ time & & $\begin{array}{l}0.092^{* *} \\
(0.034)\end{array}$ & & $\begin{array}{c}0.066^{* * *} \\
(0.019)\end{array}$ \\
\hline Observations & 736 & 736 & 748 & 748 \\
\hline$R^{2}$ & 0.724 & 0.801 & 0.538 & 0.609 \\
\hline Country FE & Yes & Yes & Yes & Yes \\
\hline Controls & No & No & No & No \\
\hline
\end{tabular}

Note: Standard errors in parentheses, clustered at country-level. The unit of observation in column (1) and (2) is the share of manufacturing and construction employment. The unit of observation in column (3) and (4) is the share of value added from manufacturing and construction. The variable time is the number of quarters. GR is a country-specific dummy variable taking value one for periods in which a country is experiencing the Great Recession. Between GR and SDC is a country-specific dummy variable taking value one for periods in which a country is in between the GR and the Sovereign Debt Crisis. SDC is a country-specific dummy variable taking vale one for periods in which a country is experiencing the Sovereign Debt Crisis. After SDC is a country-specific dummy taking value one for periods after the Sovereign Debt Crisis. $*, * *, * * *$ indicate significance at $90 \%, 95 \%$ and $99 \%$ level.

\section{B.2. Sectorial Shift and ex-ante Country Characteristics}

Symmetrically to what shown in Section 3.1, here we study whether our measure of change in sectorial composition $S h i f t_{i, c}^{\text {Manuf }}$ correlates with country-specific characteristics 
as observed before each recession $c=\{G R, S D C\}$ (see Figure B.1(a) to B.1(d)). Differently from what found in Section 3.1, here we find that countries with higher level of routine employment at the peak, with faster decline in routine employment, and with higher level of core inflation at the peak of each recession tend to experience significantly a larger shift of the value added share from manufacturing and construction in the upcoming recession. Figure B.2(a) and B.2(b) show that our measure of sectorial shift correlates well with the size and length of each recession.

Fig. B.1. Pre-recession Characteristics vs. Sectorial Shift

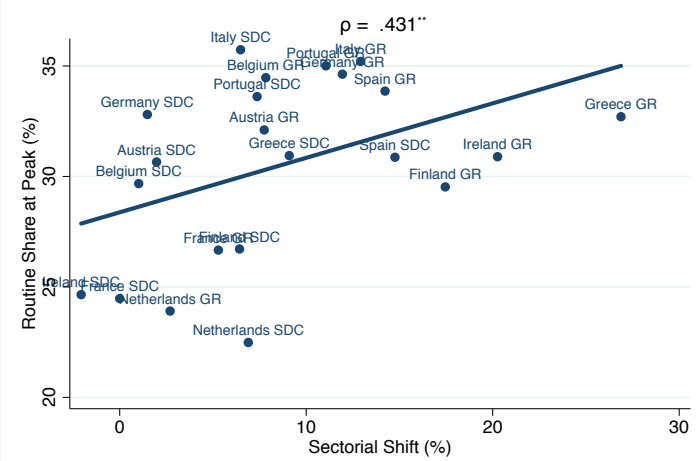

(a) Pre-recession Routine Emp.

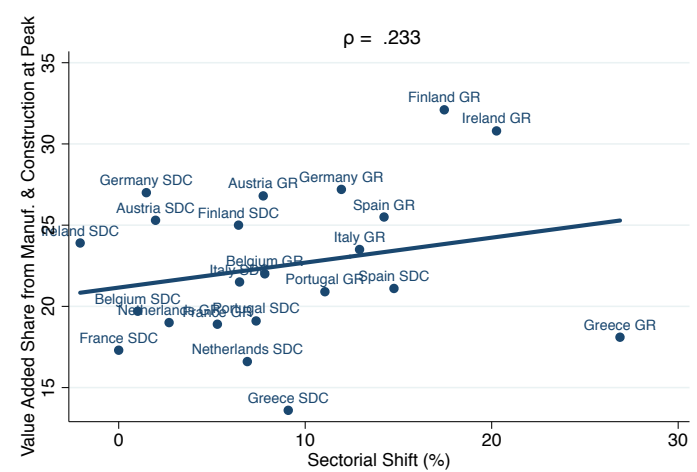

(c) Pre-recession Sectorial Composition

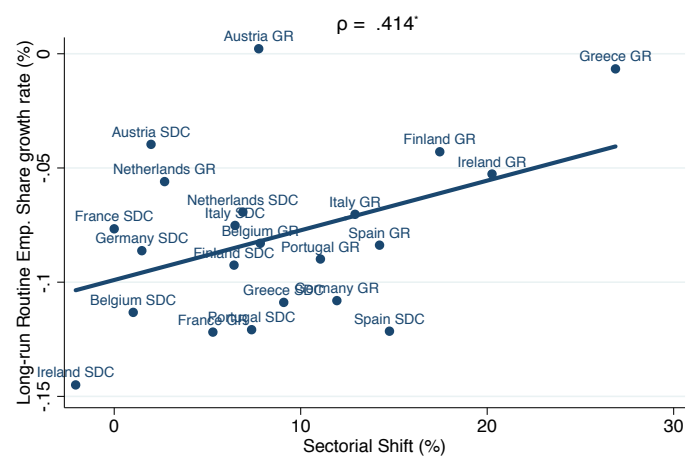

(b) Pre-recession Routine Emp. Growth

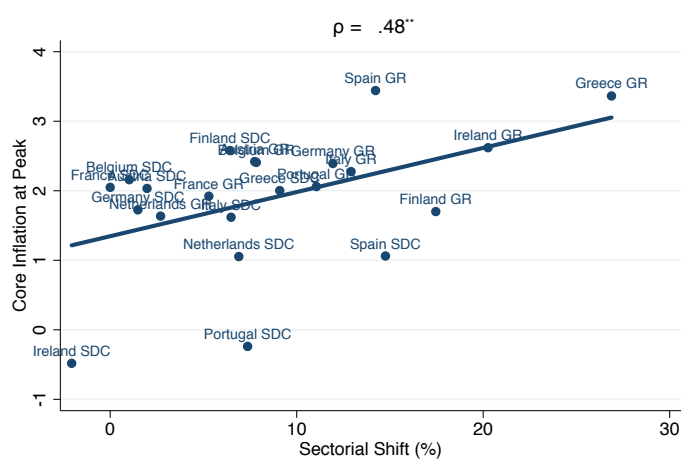

(d) Pre-recession Inflation

Note: Figure B.1(a) plots the level of the routine employment share -measured at the peak of the Great Recession (GR) and Sovereign Debt Crisis (SDC) - on the sectorial shift experienced during both downturns by each country that joined the EMU before 2002 (Luxembourg excluded). For Figure B.1(b), the y-axis is the long-run growth rate of the routine employment share, measured as the slope of the linear trend fitting the routine share series until the GR and SDC respectively. For Figure B.1(c), the $\mathrm{y}$-axis is the value added from manufacturing and construction (as percentage of Gdp), measured at the peak of the GR and SDC. For Figure B.1(d), the y-axis is the level of core inflation, measured at the peak of the GR and SDC. Each sectorial shift is defined as the percentage change in the share of value added from manufacturing and employment between the peak and trough of each recession, according to country-specific business cycle dates. On top of each graph, the correlation $(\rho)$ between variables is reported along with its significance level. *, **, *** indicate significance at $90 \%, 95 \%$ and $99 \%$ level. 
Fig. B.2. Duration and Size of the Recession vs. Sectorial Shift

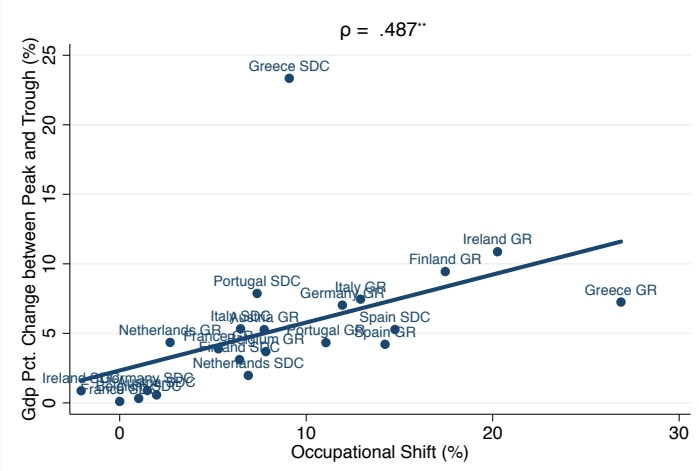

(a) GDP Contraction

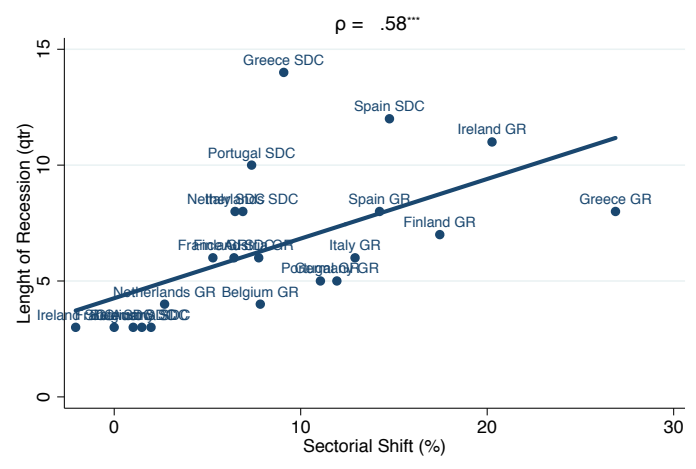

(b) Recession Duration

Note: Figure B.2(a) plots the GDP percentage change -measured between the peak and trough of the Great Recession (GR) and Sovereign Debt Crisis (SDC) - on the sectorial shift experienced during both downturns by each country that joined the EMU before 2002 (Luxembourg excluded). For Figure B.2(b) the y-axis is duration (in quarters) of each recession, measured as the number of quarters between peak and trough. Each sectorial shift is defined as the percentage change in the share of value added from manufacturing and employment between the peak and trough of each recession, according to country-specific business cycle dates. On top of each graph, the correlation $(\rho)$ between variables is reported along with its significance level. $*, * *, * * *$ indicate significance at $90 \%, 95 \%$ and $99 \%$ level.

\section{Appendix C. Model Derivation}

Here we derive the price Phillips Curve from Blanchard and Galí (2010) in log-deviations from steady state (lower case letters with hats) in the reduced and extended formulation. Equation 8 becomes

$$
\pi_{t}=\beta E_{t}\left\{\pi_{t+1}\right\}+\lambda \widehat{m c}_{t} \quad \text { where } \quad \lambda \equiv \frac{(1-\beta \theta)(1-\theta)}{\theta}
$$

and therefore we need to focus on the expression for the marginal cost. 


\section{C.1. Log-linearized Phillips Curve: Reduced Formulation}

$$
\begin{aligned}
& M C_{t}=\Theta A_{t}^{-\gamma}+B x_{t}^{\alpha}-\beta(1-\delta) E_{t}\left\{\frac{C_{t}}{C_{t+1}} \frac{A_{t+1}}{A_{t}} B x_{t+1}^{\alpha}\right\} \\
& M C \exp \left(\widehat{m c}_{t}\right)= \\
& \quad=\Theta A^{-\gamma} \exp \left(-\gamma \widehat{a}_{t}\right)+B x^{\alpha} \exp \left(\alpha \widehat{x}_{t}\right)-\beta(1-\delta) B x^{\alpha} \exp \left(\left(\widehat{c}_{t}-\widehat{a}_{t}\right)-\left(\widehat{c}_{t+1}-\widehat{a}_{t+1}\right)+\alpha \widehat{x}_{t+1}\right)
\end{aligned}
$$

which in log deviation gives :

$$
\begin{aligned}
& M C+M C \widehat{m c}_{t}=\Theta A^{-\gamma}-\Theta A^{-\gamma} \gamma \widehat{a}_{t}+ \\
& \quad+B x^{\alpha}+B x_{t}^{\alpha} \alpha \widehat{x}_{t}-\beta(1-\delta) B x^{\alpha}-\beta(1-\delta) B x^{\alpha}\left(\left(\widehat{c}_{t}-\widehat{a}_{t}\right)-\left(\widehat{c}_{t+1}-\widehat{a}_{t+1}\right)+\alpha \widehat{x}_{t+1}\right)
\end{aligned}
$$

which in steady state becomes

$$
\begin{aligned}
& M C=\Theta A^{-\gamma}+B x^{\alpha}-\beta(1-\delta) B x^{\alpha} \\
& M C=\Theta A^{-\gamma}+B x^{\alpha}(1-\beta(1-\delta)) \text { but } \Theta=\left(\frac{1}{\mu}-(1-\beta(1-\delta)) B x^{\alpha}\right) A^{\gamma} \\
& M C=\frac{1}{\mu}-\left(1-\beta(1-\delta) B x^{\alpha}\right)+(1-\beta(1-\delta)) B x^{\alpha} \\
& M C=\frac{1}{\mu}
\end{aligned}
$$

then it becomes

$$
\begin{aligned}
\frac{1}{\mu} \widehat{m c}_{t}=-\left(\frac{1}{\mu}-\right. & \left.(1-\beta(1-\delta)) B x^{\alpha}\right) \gamma \widehat{a}_{t}+ \\
& +B x^{\alpha} \alpha \widehat{x}_{t}-\beta(1-\delta) B x^{\alpha}\left(\left(\widehat{c}_{t}-\widehat{a}_{t}\right)-\left(\widehat{c}_{t+1}-\widehat{a}_{t+1}\right)+\alpha \widehat{x}_{t+1}\right)
\end{aligned}
$$

and remembering that $g=B x^{\alpha}$

$\widehat{m c}_{t}=-(1-\mu(1-\beta(1-\delta)) g) \gamma \widehat{a}_{t}+\mu g \alpha \widehat{x}_{t}-\beta(1-\delta) g \mu\left(\left(\widehat{c}_{t}-\widehat{a}_{t}\right)-\left(\widehat{c}_{t+1}-\widehat{a}_{t+1}\right)+\alpha \widehat{x}_{t+1}\right)$

implies

$$
\widehat{m c}_{t}=\alpha g \mu \widehat{x}_{t}-\beta(1-\delta) g \mu E_{t}\left\{\left(\widehat{c}_{t}-\widehat{a}_{t}\right)-\left(\widehat{c}_{t+1}-\widehat{a}_{t+1}\right)+\alpha \widehat{x}_{t+1}\right\}-\Phi \gamma \widehat{a}_{t}
$$

where $\Phi=\frac{\mu W}{A}=1-(1-\beta(1-\delta)) g \mu<1$

\section{C.2. Log-linearized Phillips Curve: Extended Formulation}

We start by changing the formulation of $\Theta=\left(\frac{1}{\mu}-(1-\beta(1-\delta)) B x^{\alpha}\right) A^{\gamma} W^{-\gamma}$ 


$$
\begin{aligned}
& M C_{t}=\Theta A_{t}^{-\gamma} W_{t-1}^{\gamma}+B x_{t}^{\alpha}-\beta(1-\delta) E_{t}\left\{\frac{C_{t}}{C_{t+1}} \frac{A_{t+1}}{A_{t}} B x_{t+1}^{\alpha}\right\} \\
& M C \exp \left(\widehat{m c}_{t}\right)= \\
& =\Theta A^{-\gamma} W^{\gamma} \exp \left(-\gamma \widehat{a}_{t}+\gamma \widehat{w}_{t-1}\right)+B x^{\alpha} \exp \left(\alpha \widehat{x}_{t}\right)-\beta(1-\delta) B x^{\alpha} \exp \left(\left(\widehat{c}_{t}-\widehat{a}_{t}\right)-\left(\widehat{c}_{t+1}-\widehat{a}_{t+1}\right)+\alpha \widehat{x}_{t+1}\right) \\
& M C+M C \widehat{m c}_{t}=\Theta A^{-\gamma} W^{\gamma}-\Theta A^{-\gamma} W^{\gamma} \gamma \widehat{a}_{t}+\Theta A^{-\gamma} W^{\gamma} \gamma \widehat{w}_{t-1}+B x^{\alpha}+ \\
& \quad B x_{t}^{\alpha} \alpha \widehat{x}_{t}-\beta(1-\delta) B x^{\alpha}-\beta(1-\delta) B x^{\alpha}\left(\left(\widehat{c}_{t}-\widehat{a}_{t}\right)-\left(\widehat{c}_{t+1}-\widehat{a}_{t+1}\right)+\alpha \widehat{x}_{t+1}\right)
\end{aligned}
$$

which in steady state becomes

$$
\begin{aligned}
& M C=\Theta A^{-\gamma} W^{\gamma}+B x^{\alpha}-\beta(1-\delta) B x^{\alpha} \quad \text { but } W=\Theta^{\frac{1}{1-\gamma}} A \\
& M C=\Theta A^{-\gamma} W^{\gamma}+B x^{\alpha}(1-\beta(1-\delta)) \quad \text { but } \Theta=\left(\frac{1}{\mu}-(1-\beta(1-\delta)) B x^{\alpha}\right) A^{\gamma} W^{-\gamma} \\
& M C=\frac{1}{\mu}-\left(1-\beta(1-\delta) B x^{\alpha}\right) W^{\gamma}+(1-\beta(1-\delta)) B x^{\alpha} \\
& M C=\frac{1}{\mu}
\end{aligned}
$$

We therefore can rewrite it as :

$$
\begin{aligned}
& M C \widehat{m c}_{t}= \\
& \quad=-\Theta A^{-\gamma} W^{\gamma} \gamma \widehat{a}_{t}+\Theta A^{-\gamma} W^{\gamma} \gamma \widehat{w}_{t-1}+B x_{t}^{\alpha} \alpha \widehat{x}_{t}-\beta(1-\delta) B x^{\alpha}\left(\left(\widehat{c}_{t}-\widehat{a}_{t}\right)-\left(\widehat{c}_{t+1}-\widehat{a}_{t+1}\right)+\alpha \widehat{x}_{t+1}\right) \\
& \frac{1}{\mu} \widehat{m c}_{t}=-\left(\frac{1}{\mu}-(1-\beta(1-\delta)) B x^{\alpha}\right) \gamma \widehat{a}_{t}+ \\
& \quad+\left(\frac{1}{\mu}-(1-\beta(1-\delta)) B x^{\alpha}\right) \gamma \widehat{w}_{t-1}+B x^{\alpha} \alpha \widehat{x}_{t}-\beta(1-\delta) B x^{\alpha}\left(\left(\widehat{c}_{t}-\widehat{a}_{t}\right)-\left(\widehat{c}_{t+1}-\widehat{a}_{t+1}\right)+\alpha \widehat{x}_{t+1}\right)
\end{aligned}
$$

Then remembering that $g=B x^{\alpha}$

$$
\begin{array}{r}
\widehat{m c}_{t}=-(1-\mu(1-\beta(1-\delta)) g) \gamma \widehat{a}_{t}+(1-\mu(1-\beta(1-\delta)) g) \gamma \widehat{w}_{t-1}+ \\
+\mu g \alpha \widehat{x}_{t}-\beta(1-\delta) g \mu\left(\left(\widehat{c}_{t}-\widehat{a}_{t}\right)-\left(\widehat{c}_{t+1}-\widehat{a}_{t+1}\right)+\alpha \widehat{x}_{t+1}\right)
\end{array}
$$

we arrive to 


$$
\widehat{m c}_{t}=\alpha g \mu \widehat{x}_{t}-\beta(1-\delta) g \mu E_{t}\left\{\left(\widehat{c}_{t}-\widehat{a}_{t}\right)-\left(\widehat{c}_{t+1}-\widehat{a}_{t+1}\right)+\alpha \widehat{x}_{t+1}\right\}-\Phi \gamma \widehat{a}_{t}+\Phi \gamma \widehat{w}_{t-1}
$$

Now consider:

$$
\begin{aligned}
& \delta \widehat{x}_{t}=\widehat{n}_{t}-(1-\delta)(1-x) \widehat{n}_{t-1} \\
& \widehat{c}_{t}=\widehat{a}_{t}+\frac{1-g}{1-\delta g} \widehat{n}_{t}+\frac{g(1-\delta)}{1-\delta g} \widehat{n}_{t-1}-\frac{\alpha g}{1-\delta g} \delta \widehat{x}_{t} \\
& \widehat{c}_{t}=E_{t}\left\{\widehat{c}_{t+1}\right\}-\left(i_{t}-E_{t}\left\{\pi_{t+1}\right\}-\rho\right) \quad \text { where } \rho=-\log \beta \\
& \widehat{u}_{t}=-(1-u) \widehat{n}_{t} \quad \text { implying } \widehat{n}_{t}=-\frac{1}{(1-u)} \widehat{u}_{t}
\end{aligned}
$$

which combined with equation C.16 becomes

$$
\begin{gathered}
\delta \widehat{x}_{t}=-\frac{1}{(1-u)} \widehat{u}_{t}+\frac{(1-\delta)(1-x)}{(1-u)} \widehat{u}_{t-1} \\
\delta(1-u) \widehat{x}_{t}=-\widehat{u}_{t}+(1-\delta)(1-x) \widehat{u}_{t-1}
\end{gathered}
$$

Combining equation C.16 with equation C.17 gives:

$$
\begin{aligned}
\widehat{c}_{t} & =\widehat{a}_{t}+\frac{1-g}{1-\delta g} \widehat{n}_{t}+\frac{g(1-\delta)}{1-\delta g} \widehat{n}_{t-1}-\frac{\alpha g}{1-\delta g} \widehat{n}_{t}+\frac{\alpha g}{1-\delta g}(1-\delta)(1-x) \widehat{n}_{t-1} \\
\widehat{c}_{t} & =\widehat{a}_{t}+\frac{1-g-\alpha g}{1-\delta g} \widehat{n}_{t}+\frac{g(1-\delta)(1+\alpha(1-x))}{1-\delta g} \widehat{n}_{t-1}
\end{aligned}
$$

that can be rewritten as :

$$
\widehat{c}_{t}=\widehat{a}_{t}+\xi_{0} \widehat{n}_{t}+\xi_{1} \widehat{n}_{t-1}
$$

where

$$
\begin{aligned}
\xi_{0} & =\frac{1-g(1+\alpha)}{1-\delta g} \\
\xi_{1} & =\frac{g(1-\delta)(1+\alpha(1-x))}{1-\delta g}
\end{aligned}
$$

Now combine equation C.21 with equation C.16 into equation C.15 


$$
\begin{aligned}
\widehat{m c}_{t} & =\alpha g \mu \widehat{x}_{t}-\beta(1-\delta) g \mu E_{t}\left\{\left(\widehat{c}_{t}-\widehat{a}_{t}\right)-\left(\widehat{c}_{t+1}-\widehat{a}_{t+1}\right)+\alpha \widehat{x}_{t+1}\right\}-\Phi \gamma \widehat{a}_{t} \\
\widehat{m c}_{t} & =\alpha g \mu\left(\frac{\widehat{n}_{t}-(1-\delta)(1-x) \widehat{n}_{t-1}}{\delta}\right)+ \\
& -\beta(1-\delta) g \mu E_{t}\left\{\left(\xi_{0} \widehat{n}_{t}+\xi_{1} \widehat{n}_{t-1}\right)-\left(\xi_{0} \widehat{n}_{t+1}+\xi_{1} \widehat{n}_{t}\right)+\alpha\left(\frac{\widehat{n}_{t+1}-(1-\delta)(1-x) \widehat{n}_{t}}{\delta}\right)\right\}-\Phi \gamma \widehat{a}_{t} \\
\widehat{m c}_{t} & =\frac{\alpha g \mu}{\delta} \widehat{n}_{t}-\frac{\alpha g \mu}{\delta}(1-\delta)(1-x) \widehat{n}_{t-1}+ \\
& -\beta(1-\delta) g \mu E_{t}\left\{\left(\xi_{0}-\xi_{1}\right) \widehat{n}_{t}+\xi_{1} \widehat{n}_{t-1}-\xi_{0} \widehat{n}_{t+1}+\frac{\alpha}{\delta} \widehat{n}_{t+1}-\frac{\alpha}{\delta}(1-\delta)(1-x) \widehat{n}_{t}\right\}-\Phi \gamma \widehat{a}_{t} \\
\widehat{m c}_{t} & =\frac{\alpha g \mu}{\delta} \widehat{n}_{t}-\frac{\alpha g \mu}{\delta}(1-\delta)(1-x) \widehat{n}_{t-1}+ \\
& -\beta(1-\delta) g \mu E_{t}\left\{\left(-\frac{\alpha}{\delta}(1-\delta)(1-x)+\xi_{0}-\xi_{1}\right) \widehat{n}_{t}+\xi_{1} \widehat{n}_{t-1}-\left(\xi_{0}-\frac{\alpha}{\delta}\right) \widehat{n}_{t+1}\right\}-\Phi \gamma \widehat{a}_{t} \\
\widehat{m c}_{t} & =\left(\frac{\alpha g \mu}{\delta}+\beta(1-\delta) g \mu\left[\frac{\alpha}{\delta}(1-\delta)(1-x)-\xi_{0}+\xi_{1}\right]\right) \widehat{n}_{t}+ \\
& -\left[\frac{\alpha g \mu}{\delta}(1-\delta)(1-x)+\beta(1-\delta) g \mu \xi_{1}\right] \widehat{n}_{t-1}+\beta(1-\delta) g \mu\left(\xi_{0}-\frac{\alpha}{\delta}\right) E_{t}\left\{\widehat{n}_{t+1}\right\}-\Phi \gamma \widehat{a}_{t} \\
\widehat{m c}_{t} & =h_{0} \widehat{n}_{t}-h_{1} \widehat{n}_{t-1}-h_{F} E_{t}\left\{\widehat{n}_{t+1}\right\}-\Phi \gamma \widehat{a}_{t}
\end{aligned}
$$

where:

$$
\begin{aligned}
& h_{0} \equiv \frac{\alpha g \mu}{\delta}\left[1+\beta(1-\delta)^{2}(1-x)\right]+\beta(1-\delta) g \mu\left(\xi_{1}-\xi_{0}\right) \\
& h_{1} \equiv \frac{\alpha g \mu}{\delta}(1-\delta)(1-x)-\beta(1-\delta) g \mu \xi_{1} \\
& h_{F} \equiv \beta(1-\delta) g \mu\left(\frac{\alpha}{\delta}-\xi_{0}\right)
\end{aligned}
$$

Now, using $\widehat{n}_{t}=-\frac{1}{(1-u)} \widehat{u}_{t}$

$$
\begin{aligned}
& \widehat{m c}_{t}=h_{0}\left(-\frac{1}{(1-u)} \widehat{u}_{t}\right)-h_{1}\left(-\frac{1}{(1-u)} \widehat{u}_{t-1}\right)-h_{F} E_{t}\left\{-\frac{1}{(1-u)} \widehat{u}_{t+1}\right\}-\Phi \gamma \widehat{a}_{t} \\
& \widehat{m c}_{t}=-\frac{h_{0}}{(1-u)} \widehat{u}_{t}+\frac{h_{1}}{(1-u)} \widehat{u}_{t-1}+\frac{h_{F}}{(1-u)} E_{t}\left\{\widehat{u}_{t+1}\right\}-\Phi \gamma \widehat{a}_{t} \\
& \widehat{m c}_{t}=-\frac{h_{0}}{(1-u)} \widehat{u}_{t}+\frac{h_{1}}{(1-u)} \widehat{u}_{t-1}+\frac{h_{F}}{(1-u)} E_{t}\left\{\widehat{u}_{t+1}\right\}-\Phi \gamma \widehat{a}_{t}
\end{aligned}
$$

Substitute in the pricing equation:

$$
\begin{aligned}
& \pi_{t}=\beta E_{t}\left\{\pi_{t+1}\right\}-\frac{\lambda h_{0}}{(1-u)} \widehat{u}_{t}+\frac{\lambda h_{1}}{(1-u)} \widehat{u}_{t-1}+\frac{\lambda h_{F}}{(1-u)} E_{t}\left\{\widehat{u}_{t+1}\right\}-\lambda \Phi \gamma \widehat{a}_{t} \\
& \pi_{t}=\beta E_{t}\left\{\pi_{t+1}\right\}-\kappa_{0} \widehat{u}_{t}+\kappa_{1} \widehat{u}_{t-1}+\kappa_{F} E_{t}\left\{\widehat{u}_{t+1}\right\}-\lambda \Phi \gamma \widehat{a}_{t}
\end{aligned}
$$


where

$$
\kappa_{0}=\frac{\lambda h_{0}}{(1-u)} \quad ; \quad \kappa_{1}=\frac{\lambda h_{1}}{(1-u)} \quad ; \quad \kappa_{F}=\frac{\lambda h_{F}}{(1-u)}
$$

\section{Appendix D. Robustness Checks for Sample Selection and Variable Definition}

\section{D.1. Checks for the Price Phillips Curve}

Are the results of Section 3.3 driven by our measures of inflation, unemployment gap, or by sample selection? Here, we show that this is not the case. In Table D.1 we repeat recursively the estimation of equation 4 (i) by excluding (including) peripheral countries (Greece, Ireland, Portugal) from the sample, (ii) by excluding (including) at least one between energy and food prices in the calculation of inflation, (iii) by defining the unemployment gap either as deviation of the unemployment rate from a linear trend or either as deviation from a trend extracted via Hodrick-Prescott filtering. Our results are robust: changes in the occupational structure significantly affects affect the slope of the price PC after the GR.

\section{D.2. Checks for the Wage Phillips Curve}

Are the results of Section 3.4 driven by our measures of wage inflation, unemployment gap, or by sample selection? In Table D.2 we repeat recursively the estimation of the wage PC (i) by excluding (including) peripheral countries (Greece, Ireland, Portugal) from the sample, (ii) by excluding (including) at the component of wage inflation explained by manufacturing and construction, (iii) by defining the unemployment gap either as deviation of the unemployment rate from a linear trend or either as deviation from a trend extracted via Hodrick-Prescott filtering. All in all, these robustness checks confirm that occupational shifts never play a role in explaining the slope of the wage PC. On the contrary, sectorial shifts seems to be important for the slope of the wage PC. This result does not depend on the definition of unemployment gap or wage inflation. Yet, when dropping peripheral countries, we do not find any significant effect if the unemployment gap is defined as the HP-filtered unemployment rate. 
Table D.1: The Flattening of the Price Phillips Curve across the EMU11 - Robustness Checks

\begin{tabular}{|c|c|c|c|c|c|c|c|c|c|c|c|}
\hline & $\begin{array}{c}(1) \\
\Delta \log (p)\end{array}$ & $\begin{array}{c}(2) \\
\Delta \log (p)\end{array}$ & $\begin{array}{c}(3) \\
\Delta \log (p)\end{array}$ & $\begin{array}{c}(4) \\
\Delta \log (p)\end{array}$ & $\begin{array}{c}(5) \\
\Delta \log (p)\end{array}$ & $\begin{array}{c}(6) \\
\Delta \log (p)\end{array}$ & $\begin{array}{c}(7) \\
\Delta \log (p)\end{array}$ & $\begin{array}{c}(8) \\
\Delta \log (p) \\
\end{array}$ & $\begin{array}{c}(9) \\
\Delta \log (p)\end{array}$ & $\begin{array}{c}(10) \\
\Delta \log (p)\end{array}$ & $\begin{array}{c}(11) \\
\Delta \log (p)\end{array}$ \\
\hline$u_{t-1}$ & $\begin{array}{c}-0.086^{* * *} \\
(0.021)\end{array}$ & $\begin{array}{c}-0.133^{* * *} \\
(0.008)\end{array}$ & $\begin{array}{c}-0.151^{* * *} \\
(0.022)\end{array}$ & $\begin{array}{c}-0.079^{* *} \\
(0.026)\end{array}$ & $\begin{array}{c}-0.089^{* *} \\
(0.029)\end{array}$ & $\begin{array}{c}-0.143^{* * *} \\
(0.039)\end{array}$ & $\begin{array}{c}-0.191^{* * *} \\
(0.038)\end{array}$ & $\begin{array}{c}-0.069^{* * *} \\
(0.015)\end{array}$ & $\begin{array}{c}-0.065^{* * *} \\
(0.014)\end{array}$ & $\begin{array}{c}-0.115^{* * *} \\
(0.019)\end{array}$ & $\begin{array}{c}-0.111^{* * *} \\
(0.017)\end{array}$ \\
\hline $\operatorname{After}_{G R} \times u_{t-1}$ & $\begin{array}{c}0.083^{*} \\
(0.040)\end{array}$ & $\begin{array}{l}0.099^{* *} \\
(0.034)\end{array}$ & $\begin{array}{c}0.113 \\
(0.090)\end{array}$ & $\begin{array}{c}0.043 \\
(0.046)\end{array}$ & $\begin{array}{c}0.042 \\
(0.073)\end{array}$ & $\begin{array}{c}0.138 \\
(0.092)\end{array}$ & $\begin{array}{c}0.300^{* * *} \\
(0.076)\end{array}$ & $\begin{array}{c}0.019 \\
(0.020)\end{array}$ & $\begin{array}{c}0.044 \\
(0.035)\end{array}$ & $\begin{array}{c}0.001 \\
(0.039)\end{array}$ & $\begin{array}{l}-0.035 \\
(0.104)\end{array}$ \\
\hline After $_{G R} \times$ Shift $_{G R}^{R} \times u_{t-1}$ & $\begin{array}{l}0.009^{* *} \\
(0.003)\end{array}$ & $\begin{array}{c}0.008^{*} \\
(0.004)\end{array}$ & $\begin{array}{c}0.017^{*} \\
(0.008)\end{array}$ & $\begin{array}{c}0.007^{* * *} \\
(0.001)\end{array}$ & $\begin{array}{c}0.008^{*} \\
(0.003)\end{array}$ & $\begin{array}{c}0.017^{* * *} \\
(0.003)\end{array}$ & $\begin{array}{c}0.013 \\
(0.008)\end{array}$ & $\begin{array}{c}0.004^{* * *} \\
(0.001)\end{array}$ & $\begin{array}{l}0.008^{* *} \\
(0.002)\end{array}$ & $\begin{array}{c}0.010^{* *} \\
(0.004)\end{array}$ & $\begin{array}{c}0.009^{*} \\
(0.004)\end{array}$ \\
\hline After $_{S D C} \times u_{t-1}$ & $\begin{array}{c}-0.024 \\
(0.027)\end{array}$ & $\begin{array}{l}-0.012 \\
(0.062)\end{array}$ & $\begin{array}{c}-0.019 \\
(0.122)\end{array}$ & $\begin{array}{c}-0.018 \\
(0.015)\end{array}$ & $\begin{array}{c}-0.081 \\
(0.044)\end{array}$ & $\begin{array}{l}-0.075 \\
(0.050)\end{array}$ & $\begin{array}{c}-0.200^{*} \\
(0.088)\end{array}$ & $\begin{array}{c}0.013 \\
(0.012)\end{array}$ & $\begin{array}{c}0.002 \\
(0.023)\end{array}$ & $\begin{array}{c}-0.038 \\
(0.048)\end{array}$ & $\begin{array}{c}-0.007 \\
(0.114)\end{array}$ \\
\hline After $_{S D C} \times$ Shift $_{S D C}^{R} \times u_{t-1}$ & $\begin{array}{c}0.021^{* * *} \\
(0.003)\end{array}$ & $\begin{array}{c}0.030^{* *} \\
(0.012)\end{array}$ & $\begin{array}{c}0.044^{* *} \\
(0.014)\end{array}$ & $\begin{array}{c}0.015^{* * *} \\
(0.003)\end{array}$ & $\begin{array}{c}0.013^{*} \\
(0.006)\end{array}$ & $\begin{array}{c}0.040^{* * *} \\
(0.008)\end{array}$ & $\begin{array}{c}0.046^{* *} \\
(0.015)\end{array}$ & $\begin{array}{c}0.009^{* * *} \\
(0.002)\end{array}$ & $\begin{array}{c}0.013^{* * *} \\
(0.002)\end{array}$ & $\begin{array}{c}0.027^{* *} \\
(0.010)\end{array}$ & $\begin{array}{c}0.023^{*} \\
(0.011)\end{array}$ \\
\hline After $_{G R} \times$ Shift $_{G R}^{\text {Manuf }} \times u_{t-1}$ & $\begin{array}{c}-0.006 \\
(0.003)\end{array}$ & $\begin{array}{c}-0.004^{* *} \\
(0.002)\end{array}$ & $\begin{array}{c}-0.010 \\
(0.008)\end{array}$ & $\begin{array}{c}-0.003^{* * *} \\
(0.001)\end{array}$ & $\begin{array}{c}-0.004 \\
(0.006)\end{array}$ & $\begin{array}{c}-0.010^{* * *} \\
(0.002)\end{array}$ & $\begin{array}{c}-0.015^{* * *} \\
(0.004)\end{array}$ & $\begin{array}{c}-0.001 \\
(0.001)\end{array}$ & $\begin{array}{l}-0.005 \\
(0.003)\end{array}$ & $\begin{array}{l}-0.001 \\
(0.002)\end{array}$ & $\begin{array}{c}0.003 \\
(0.008)\end{array}$ \\
\hline After $_{S D C} \times$ Shift $_{S D C}^{\text {Manuf }} \times u_{t-1}$ & $\begin{array}{c}-0.023 \\
(0.014)\end{array}$ & $\begin{array}{c}-0.107^{* * *} \\
(0.015)\end{array}$ & $\begin{array}{c}-0.127^{* *} \\
(0.044)\end{array}$ & $\begin{array}{c}-0.036^{* * *} \\
(0.010)\end{array}$ & $\begin{array}{c}0.013 \\
(0.040)\end{array}$ & $\begin{array}{c}-0.142^{* * *} \\
(0.028)\end{array}$ & $\begin{array}{c}-0.081 \\
(0.064)\end{array}$ & $\begin{array}{c}-0.022^{* * *} \\
(0.007)\end{array}$ & $\begin{array}{l}-0.031 \\
(0.017)\end{array}$ & $\begin{array}{c}-0.064^{* *} \\
(0.023)\end{array}$ & $\begin{array}{l}-0.103 \\
(0.072)\end{array}$ \\
\hline Observations & 544 & 748 & 544 & 748 & 544 & 748 & 544 & 748 & 544 & 748 & 544 \\
\hline$R^{2}$ & 0.865 & 0.898 & 0.866 & 0.852 & 0.810 & 0.850 & 0.809 & 0.895 & 0.841 & 0.894 & 0.842 \\
\hline Country FE & Yes & Yes & Yes & Yes & Yes & Yes & Yes & Yes & Yes & Yes & Yes \\
\hline Controls & Yes & Yes & Yes & Yes & Yes & Yes & Yes & Yes & Yes & Yes & Yes \\
\hline $\begin{array}{l}\text { Periphery } \\
\text { HCPI excluding: }\end{array}$ & Out & In & Out & In & Out & In & Out & In & Out & In & Out \\
\hline Energy & Yes & Yes & Yes & No & No & No & No & Yes & Yes & Yes & Yes \\
\hline Food & Yes & Yes & Yes & No & No & No & No & No & No & No & No \\
\hline Unemp. Gap & Linear & $\mathrm{HP}$ & HP & Linear & Linear & $\mathrm{HP}$ & HP & Linear & Linear & $\mathrm{HP}$ & HP \\
\hline
\end{tabular}
price index (HCPI) with energy and food goods excluded in column (1) to (3), with energy and food goods included in column (4) to (7), with energy (food) goods excluded (included) in column (9) to (11). After $G R\left(\right.$ After $\left._{S D C}\right)$ is dummy taking value one for periods after the GR (SDC) according to country-specific business-cycle dates; Shift $t_{G R}^{R}$ $\left(S h i f t_{S D C}^{R}\right)$ is the shift in the occupational structure occurred during recession GR (SDC), i.e. the percentage change in the routine employment share between the peak and trough of the recession according to country-specific business cycle dates; Shift $t_{G R}^{\text {Manuf }}$ (Shift $t_{S D C}^{\text {Manuf }}$ ) is the shift in the share of value added from manufacturing and construction occurred during recession GR (SDC), i.e. the percentage change in the share of value added from these two sectors between the peak and trough of the recession according to country-specific business cycle dates; $u_{t-1}$ is the unemployment gap measured as deviation of the unemployment series from a linear (Linear) trend (column (1), (4), (5), (8) and (9)) or as deviation of the unemployment series from its trend component extracted via Hodrick-Prescott (HP) filtering (column (2), (3), (6), (7), (10) and (11)); column (1), (3), (5), (7), (9) and (11) exclude peripheral countries (Greece, Ireland, Portugal), whereas all other columns consider all EMU11 countries. The vector of controls includes lagged inflation, past expectations on current inflation, the change in the import price index, and a dummy for each country-specific business cycle phase. The sample is composed of all countries that joined the EMU before 2002 (Luxembourg excluded). Data is quarterly. *,**,*** indicate significance at $90 \%, 95 \%$ and $99 \%$ level. 
Table D.2: The Behavior of the Wage Phillips Curve - Robustness Checks

\begin{tabular}{|c|c|c|c|c|c|c|c|}
\hline & $\begin{array}{c}(1) \\
\Delta \log (w)\end{array}$ & $\begin{array}{c}(2) \\
\Delta \log (w) \\
\end{array}$ & $\begin{array}{c}(3) \\
\Delta \log (w) \\
\end{array}$ & $\begin{array}{c}(4) \\
\Delta \log (w)\end{array}$ & $\begin{array}{c}(5) \\
\Delta \log (w)\end{array}$ & $\begin{array}{c}(6) \\
\Delta \log (w)\end{array}$ & $\begin{array}{c}(7) \\
\Delta \log (w)\end{array}$ \\
\hline$u_{t-1}$ & $\begin{array}{l}-0.113 \\
(0.068)\end{array}$ & $\begin{array}{l}-0.049 \\
(0.167)\end{array}$ & $\begin{array}{l}-0.270 \\
(0.414)\end{array}$ & $\begin{array}{c}0.000 \\
(0.075)\end{array}$ & $\begin{array}{l}-0.036 \\
(0.075)\end{array}$ & $\begin{array}{c}0.010 \\
(0.202)\end{array}$ & $\begin{array}{l}-0.225 \\
(0.410)\end{array}$ \\
\hline After $_{G R} \times u_{t-1}$ & $\begin{array}{c}0.411^{*} \\
(0.181)\end{array}$ & $\begin{array}{c}0.334 \\
(0.406)\end{array}$ & $\begin{array}{c}0.525 \\
(0.683)\end{array}$ & $\begin{array}{c}0.132 \\
(0.085)\end{array}$ & $\begin{array}{c}0.424^{*} \\
(0.176)\end{array}$ & $\begin{array}{c}0.409 \\
(0.429)\end{array}$ & $\begin{array}{c}0.406 \\
(0.646)\end{array}$ \\
\hline After $_{G R} \times$ Shift $_{G R}^{R} \times u_{t-1}$ & $\begin{array}{c}-0.023 \\
(0.092)\end{array}$ & $\begin{array}{c}0.064 \\
(0.043)\end{array}$ & $\begin{array}{l}-0.225 \\
(0.171)\end{array}$ & $\begin{array}{c}0.018 \\
(0.013)\end{array}$ & $\begin{array}{l}-0.005 \\
(0.091)\end{array}$ & $\begin{array}{c}0.044 \\
(0.040)\end{array}$ & $\begin{array}{c}-0.181 \\
(0.127)\end{array}$ \\
\hline After $_{S D C} \times u_{t-1}$ & $\begin{array}{c}-0.369 \\
(0.337)\end{array}$ & $\begin{array}{c}-0.626^{* * *} \\
(0.121)\end{array}$ & $\begin{array}{c}-0.960 \\
(0.859)\end{array}$ & $\begin{array}{c}-0.105^{*} \\
(0.038)\end{array}$ & $\begin{array}{l}-0.477 \\
(0.332)\end{array}$ & $\begin{array}{c}-0.695^{* * *} \\
(0.085)\end{array}$ & $\begin{array}{c}-0.913 \\
(0.652)\end{array}$ \\
\hline After $_{S D C} \times$ Shift $_{S D C}^{R} \times u_{t-1}$ & $\begin{array}{c}0.066 \\
(0.046)\end{array}$ & $\begin{array}{c}0.029 \\
(0.068)\end{array}$ & $\begin{array}{c}-0.027 \\
(0.108)\end{array}$ & $\begin{array}{c}-0.009 \\
(0.026)\end{array}$ & $\begin{array}{c}0.065 \\
(0.046)\end{array}$ & $\begin{array}{c}0.022 \\
(0.064)\end{array}$ & $\begin{array}{c}-0.035 \\
(0.083)\end{array}$ \\
\hline After $_{G R} \times$ Shift $_{G R}^{\text {Manuf }} \times u_{t-1}$ & $\begin{array}{c}-0.037^{* * *} \\
(0.007)\end{array}$ & $\begin{array}{c}-0.063^{* *} \\
(0.014)\end{array}$ & $\begin{array}{c}0.028 \\
(0.053)\end{array}$ & $\begin{array}{c}-0.019^{* *} \\
(0.006)\end{array}$ & $\begin{array}{c}-0.034^{* *} \\
(0.009)\end{array}$ & $\begin{array}{c}-0.049^{* * *} \\
(0.010)\end{array}$ & $\begin{array}{c}0.040 \\
(0.044)\end{array}$ \\
\hline After $_{S D C} \times S h i f t_{S D C}^{\text {Manuf }} \times u_{t-1}$ & $\begin{array}{c}0.012 \\
(0.096)\end{array}$ & $\begin{array}{c}0.118 \\
(0.094)\end{array}$ & $\begin{array}{c}0.370 \\
(0.284)\end{array}$ & $\begin{array}{c}0.009 \\
(0.026)\end{array}$ & $\begin{array}{c}0.014 \\
(0.086)\end{array}$ & $\begin{array}{c}0.110 \\
(0.082)\end{array}$ & $\begin{array}{c}0.398 \\
(0.189)\end{array}$ \\
\hline Observations & 500 & 680 & 500 & 680 & 500 & 680 & 500 \\
\hline$R^{2}$ & 0.479 & 0.542 & 0.451 & 0.363 & 0.316 & 0.367 & 0.327 \\
\hline Country FE & Yes & Yes & Yes & Yes & Yes & Yes & Yes \\
\hline Controls & Yes & Yes & Yes & Yes & Yes & Yes & Yes \\
\hline Periphery & Out & In & Out & In & Out & In & Out \\
\hline $\begin{array}{l}\text { Labor Cost Index excluding: } \\
\text { Manuf. \& Construction } \\
\text { Unemp. Gap }\end{array}$ & $\begin{array}{c}\text { No } \\
\text { Linear }\end{array}$ & $\begin{array}{l}\text { No } \\
\mathrm{HP}\end{array}$ & $\begin{array}{l}\text { No } \\
\mathrm{HP}\end{array}$ & $\begin{array}{l}\text { Yes } \\
\text { Linear }\end{array}$ & $\begin{array}{c}\text { Yes } \\
\text { Linear }\end{array}$ & $\begin{array}{l}\text { Yes } \\
\text { HP }\end{array}$ & $\begin{array}{l}\text { Yes } \\
\mathrm{HP}\end{array}$ \\
\hline
\end{tabular}

Note: Standard errors in parentheses, clustered at country-level. In column (1) to (3), the unit of observation is wage inflation, measured as the year-on-year log-change of the labor-cost index (salary and wages) for the business economy. In column (4)-(7), we exclude the component of wage inflation explained by the manufacturing and construction sector. After $_{G R}\left(\right.$ After $_{S D C}$ ) is dummy taking value one for periods after the GR (SDC) according to country-specific businesscycle dates; Shift $t_{G R}^{R}\left(\right.$ Shift $\left.t_{S D C}^{R}\right)$ is the shift in the occupational structure occurred during recession GR (SDC), i.e. the percentage change in the routine employment share between the peak and trough of the recession according to countryspecific business cycle dates; Shift ${ }_{G R}^{\text {Manuf }}\left(\right.$ Shift $\left._{S D C}^{\text {Manuf }}\right)$ is the shift in the share of value added from manufacturing and construction occurred during recession GR (SDC), i.e. the percentage change in the share of value added from these two sectors between the peak and trough of the recession according to country-specific business cycle dates; $u_{t-1}$ is the unemployment gap measured as deviation of the unemployment series from a linear (Linear) trend (column (1), (4) and (5)) or as deviation of the unemployment series from its trend component extracted via Hodrick-Prescott (HP) filtering (column (2), (3), (6) and (7)); column (1), (3), (5) and (7) exclude peripheral countries (Greece, Ireland, Portugal), whereas all other columns consider all EMU11 countries. The vector of controls includes past expectations on current wage inflation (measured as a four quarters moving average), and a dummy for each country-specific business cycle phase. The sample is composed of all countries that joined the EMU before 2002 (Luxembourg excluded). Data is quarterly. *, **, *** indicate significance at $90 \%, 95 \%$ and $99 \%$ level. 


\section{Appendix E. Hiring Rate across the EMU11 and Jobs}

Figure E.1 plots the job-specific mean hiring rate (with $95 \%$ confidence interval) across the EMU11. This is done for two different sub-periods: before the GR (between 2002 and 2007) and after the Sovereign Debt Crisis (between 2014 and 2018). Each job-specific flow from unemployment to employment is build as $h_{t}=\left[n_{t+1}-(1-\delta) n_{t}\right]$, with $n$ being the jobspecific employment rate and $\delta$ being the job-specific separation rate. $\delta$ is build as explained in Section 4.3. We consider only positive values of $h_{t}$.

As shown in the figure, before the GR the abstract market exhibits a hiring rate which is (significantly) twice the rate of other segments of the labor market. Yet, the level of hiring in the abstract market before the GR and after the SDC are statistically equal. On the contrary, the hiring rate in the routine and manual market are significantly lower in postSDC periods, such that the aggregate hiring rate (the sum of the three rates) is lower with respect to pre-GR periods.

From the theoretical model we know that a higher $\delta$ implies a higher hiring rate, ceteris paribus. Figure E.1 shows that actually this is not the case. This could be due to a deterioration of aggregate matching efficiency (the parameter $B$ in our model) in post-GR years. This fact is widely documented both in the US and Europe through the analysis of the Beveridge curve and its shift-out in recent years.

Fig. E.1. Mean Hiring Rate by Occupation across EMU11

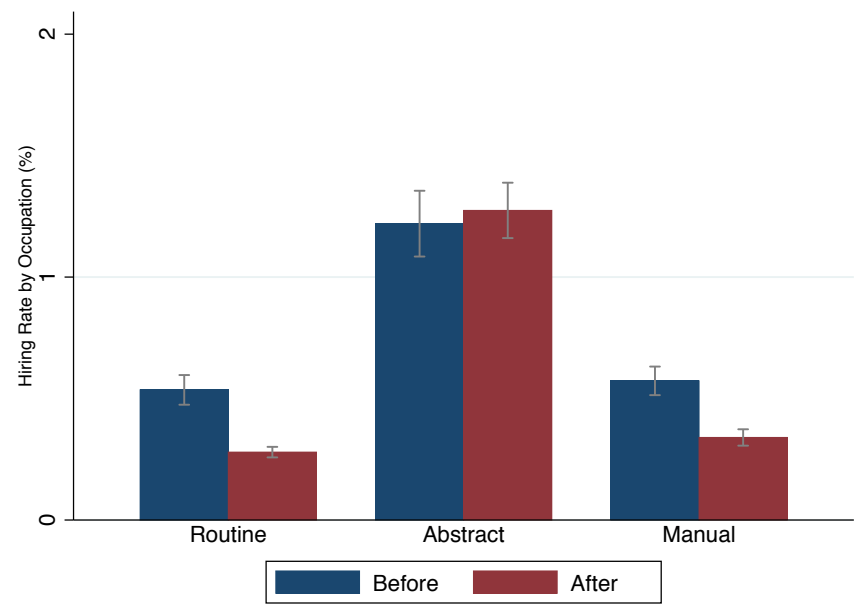

Note: Figure E.1 plots the mean hiring rate (with $95 \%$ confidence interval) by occupation (routine, abstract or manual) across countries that joined the EMU before 2002 (Luxembourg excluded). Each job-specific flow from unemployment to employment is build as $h_{t}=\left[n_{t+1}-(1-\delta) n_{t}\right]$, with $n$ being the job-specific employment rate and $\delta$ being the job-specific separation rate. The latter is built by studying the (last) job composition and duration of the unemployment pool in each year and country. This allows to identify correctly the timing and size of flows from each job to unemployment, which is finally normalized by the level of total employment in the previous period. We consider only positive values of $h_{t}$ and we compute cross-country means in two periods in time: before the Great Recession (between 2002 and 2007) and after the Sovereign Debt Crisis (between 2014 and 2018). 